\title{
Large-Scale Fields and Flows in the Magnetosphere-Ionosphere System
}

M Lockwood

September 1994 
DRAL is part of the Engineering and Physical Sciences Research Council

The Engineering and Physical Sciences Research Council does not accept any responsibility for loss or damage arising from the use of information contained in any of its reports or in any communication about its tests or investigations 


\title{
LARGE-SCALE FIELDS AND FLOWS IN THE MAGNETOSPHERE-IONOSPHERE SYSTEM•
}

\author{
M Lockwood* \\ (Rutherford Appleton Laboratory, Chilton, Didcot, OX11 OQX, UK) \\ *Also Visiting Honorary Lecturer at Imperial College, London, UK
}

- Reporter review, presented to Commission III of the International Association of Geomagnetism and Aeronomy at 7th IAGA Scientific Assembly, Buenos Aires, Argentina,

- In press, to appear in "Surveys in Geophysics"

\begin{abstract}
Advances in our understanding of the large-scale electric and magnetic fields in the coupled magnetosphere-ionosphere system are reviewed. The literature appearing in the period January 1991-June 1993 is sorted into 8 general areas of study. The phenomenon of substorms receives the most attention in this literature, with the location of onset being the single most discussed issue. However, if the magnetic topology in substorm phases was widely debated, less attention was paid to the relationship of convection to the substorm cycle. A significantly new consensus view of substorm expansion and recovery phases emerged, which was termed the 'Kiruna Conjecture' after the conference at which it gained widespread acceptance. The second largest area of interest was dayside transient events, both near the magnetopause and the ionosphere. It became apparent that these phenomena include at least two classes of events, probably due to transient reconnection bursts and sudden solar wind dynamic pressure changes. The contribution of both types of event to convection is controversial. The realisation that induction effects decouple electric fields in the magnetosphere and ionosphere, on time scales shorter than several substorm cycles, calls for broadening of the range of measurement techniques in both the ionosphere and at the magnetopause. Several new techniques were introduced including ionospheric observations which yield reconnection rate as a function of time. The magnetospheric and ionospheric behaviour due to various quasi-steady interplanetary conditions was studied using magnetic cloud events. For northward IMF conditions, reverse convection in the polar cap was found to be predominantly a summer hemisphere phenomenon and even for extremely rare prolonged southward IMF conditions, the magnetosphere was observed to oscillate through various substorm cycles rather than forming a steady-state convection bay.
\end{abstract}

\section{Statistics of Publications}

This review surveys all the relevant literature published in 7 journals during the period January 1991-June 1993. In addition, papers appearing elsewhere or in various conference publications (Adv. in Space Research, AGU Monographs, ESA SP publications, etc.) are included, but only where there is no equivalent regular journal publication. Table 1 lists the journals, the number of relevant papers and the number of journal pages they occupy. 
Table 1 Journals surveyed and numbers of papers and pages

$\begin{array}{lcc} & \text { No. of papers } & \text { No. of pages } \\ \text { J. geophys. Res. } & 158(47.4 \%) & 1825(56.5 \%) \\ \text { Geophys. Res. Lett. } & 45(13.5 \%) & 176(5.5 \%) \\ \text { Planet Space Sci. } & 19(5.7 \%) & 240(7.4 \%) \\ \text { Ann. Geophys. } & 14(4.2 \%) & 152(4.7) \\ \text { Geomag. and Aeron. } & 16(4.8 \%) & 76(2.4 \%) \\ \text { J. atmos. terr. Phys. } & 22(6.6 \%) & 279(8.6 \%) \\ \text { J. Geomag. Geoelect. } & 8(2.4 \%) & 115(3.6 \%) \\ \text { Other } & 51(15.3 \%) & 360(11.2 \%) \\ \text { Total } & 333 & 3233\end{array}$

Table 2 Numbers of papers and Journal pages for various categories of main subject

$\begin{array}{llll} & & \text { No. of papers } & \text { No. of pages } \\ \text { 1. } & \text { Measurement Techniques } & 21(6.3 \%) & 188(5.3 \%) \\ \text { 2. } & \text { Reconnection } & 35(10.5 \%) & 333(10.3 \%) \\ \text { 3. } & \text { Viscous-like Mechanisms } & 26(7.8 \%) & 235(7.3 \%) \\ \text { 4. } & \text { Magnetosphere-Ionosphere Coupling } & 15(4.5 \%) & 149(4.6 \%) \\ \text { 5. } & \text { Substorms (general) } & 95(28.6 \%) & 958(29.6 \%) \\ \text { 6. } & \text { Convection and Substorms } & 26(7.8 \%) & 229(7.1 \%) \\ \text { 7. } & \text { Flow Patterns and Variations } & 56(16.8 \%) & 570(17.6 \%) \\ \text { 8. Dayside Transients } & 59(17.7 \%) & 571(17.7 \%)\end{array}$


Table 1 shows that just under half of the papers and more than half of the journal pages, appeared in the Journal of Geophysical Research and, on behalf of the community, I express our gratitude to the American Geophysical Union for providing the main vehicle for publishing our research. However, half of the literature appears elsewhere and no scientist can afford to ignore this. My personal view of the distribution of the most significant papers is perhaps best quantified by the fact that half those I selected for the oral presentation of this review were from J. Geophys. Res. and half from all other sources.

Table 2 sorts the numbers of papers and journal pages according to 8 broad subject areas. Each paper was classified into only one area, according to my personal assessment of its most significant point (naturally, some papers could have qualified for several categories). This classification is therefore subjective. Nevertheless, Table 2 gives some guide to the relative volumes of the literature which are devoted to the different subjects. It can be seen that the single biggest subject of study was substorms, making up over a third of the literature. The next largest areas were dayside transients and the patterns and variations of the ionospheric flow.

It is instructive to further sub-divide some categories into areas of study, in order to see the trends of the research. Of the 333 pages on the subject of reconnection, 60 concerned accelerated ion flows at the magnetopause, 68 were on single $\mathrm{X}$-line versus multi-X-line configurations, and just 7 on component versus anti-parallel reconnection. A large number of pages (105) dealt with time-varying reconnection, but surprisingly few (17) with 3-dimensional reconnection.

The favourite viscous-like interaction for discussion was the Kelvin-Helmholtz instability (65 pages out of 235), compared with 63 pages on all other proposed mechanisms. A total of 20 pages dealt with the formation of the low-latitude boundary layer and 41 with the voltage across it, associated with anti-sunward flow.

The surprisingly few pages concerned specifically with magnetosphere-ionosphere coupling mechanisms (149) is misleading in that almost all papers treat the magnetosphere-ionosphere system as a coupled whole. Half of this total was concerned with induction effects decoupling the magnetospheric and ionospheric electric fields for non-steady conditions (74 pages).

The literature on substorms (958 pages) was dominated by just one issue with 367 pages concerning the location of onset. A total of 75 pages were devoted to so-called "current disruption" (CD) models of substorms, and 113 to plasmoids, the chief success of the "Near-Earth Neutral Line" (NENL) model. A growing realisation that substorms have both directly-driven and a loading/unloading character reduced debate on this subject to just 98 pages, which were mainly of a review nature.

The 570 pages on flow patterns and their variations included 104 on the effects of the interplanetary magnetic field (IMF) $\mathrm{B}_{\mathrm{y}}$ component, 113 on northward-IMF convection, and 93 on the flows around auroral arcs (particularly transpolar arcs). However the largest grouping (covering 217 pages) concerned flow variability on a range of time scales between minutes and years. 
Dayside transient events commanded a lot of interest (571 pages) with roughly one-third (150 pages) on magnetopause events and two-thirds (386 pages) on ionospheric events.

Having established the areas of interest, at least as indicated by the number of journal pages devoted to them, the remainder of this review will in the following 8 sections look at each subject area in turn.

\section{Measurement Techniques}

In this category there were a number of developments but with only two major themes emerging. There was growing interest in remote sensing of ionospheric flows to evaluate temporal effects, but also ionospheric observations were used to estimate the reconnection rates at the magnetopause and in the geomagnetic tail.

There was considerable work on the techniques for ionospheric flow determination by various radars. Freeman et al. (1991) and Yeoman et al. (1992) made, respectively, theoretical and observational assessments of the accuracy and limitations of the widely-used "L-shell fitting" techniques. Such an approximation is not needed by bistatic HF radars and the first 2-D spatial distributions of flow were reported by Hanuise et al. (1993). These results are very significant because such combined Goose Bay-Shaferville radar operations will be just one part of the SUPERDARN network to image much of the northern hemisphere auroral flow. Bistatic systems are also planned for Antarctica. The HF radars use coherent scatter from F-region irregularities. Over the past few years, it has become apparent that VHF radar scatter from the E region is more more complex than first thought. In particular, Robinson (1993) has shown how the 'saturation' of the VHF echo Doppler shift is complicated by the effects of enhanced electron temperature on the ion acoustic speed. The directions of flow deduced by a bistatic VHF system are only roughly correct and the magnitudes are seriously in error. This result has significant implications for our knowledge of ionospheric electric fields, particularly during substorms. Related to this question, Kirkwood (1992) has presented a new model for ionospheric conductivities during substorms, helping to resolve how much the magnetic signatures in the expansion phase are due to increases in the ionospheric conductivities. A method for deriving conductivities from DE-1 UV images was presented by Lummerzhein et al. (1991) and a global model by Denisenko and Zamay (1992).

The AMIE technique for producing ionospheric flow snapshots by synthesis of satellite and radar flow data with magnetogram inversion, was introduced before the review period. However, it is of great significance and importance that the technique came into more widespread use over the last two years (eg. Richmond, 1992; Knipp et al., 1991a; Knipp et al., 1993). Other applications of ground magnetometer data included the inference of the IMF $B_{y}$ (Saroso 1993) and $B_{z}$ component (Vennerstrom et al., 1991), the latter via the polar cap index. Maclennan etal. (1991) showed that $A_{E}$ indices derived from opposite hemispheres were highly correlated but that there were strong seasonal dependencies.

Carr et al. (1992) and Minnow and Smith (1993) proposed that satellite-bourne FPIs could be used to image convection in the ionosphere and the method for deriving flow from digisonde measurements was described by Cannon et al. (1991). In addition, Rosenberg et al. (1991, 1993) proposed that imaging riometers in the dayside polar cap can determine convection by observing the Ex B drift of F-region patches. 
The growing awareness that induction effects decouple magnetospheric and ionospheric electric fields (see Section 5) means that combined ionospheric and magnetospheric observations are needed, rather than mapping ionospheric electric fields along magnetic field models with the assumption of steady state. New methods for deriving magnetospheric electric fields in the central plasma sheet were presented by Li and Spieser (1991), Onsager et al. (1991) and Piel et al. (1992 a;b) from ion distribution functions, from ion velocity dispersion and from resonance cone asymmetries, respectively. In addition, Diebold et al. (1994) discussed errors introduced in electric field observations by spacecraft charging. Kelley et al. (1991) presented a new method for determining the Poynting flux.

Two new methods for determining reconnection rate were presented, both using ionospheric data. The first involves calculating the flux transport across the open/closed boundary by looking at the plasma flow in the boundary rest frame (de la Beaujardiere et al., 1991b). The main problem is that auroral images from VIKING reveal a relatively 'dark region' between the main auroral oval and the inferred polar cap boundary (see Section 6) - making identification of the open/closed boundary from the poleward edge of auroral precipitation difficult. However, because the flow is often not a strong function of latitude around the boundary, the determination of the location of the boundary may not be critical. In addition, this method requires that the motion and orientation of the boundary must also be known (see Lockwood et al., 1988). An approach by Lockwood and Cowley (1992) defined the open/closed boundary as the poleward-most reversal of equivalent current vectors and then evaluated the difference between the tangential electric fields associated with boundary motions and that associated with the plasma flow, derived by magnetogram inversion. This yields not only the length of the ionospheric merging gaps (the projections of the $\mathrm{X}$ lines) but also the reconnection voltages across them. As a check of the assumptions, the difference in the dayside and nightside voltages deduced must predict the change in the polar cap area. Various methods for calculating the area of the polar cap were compared by Mishin et al. (1992c).

The second method, introduced by Lockwood and Smith (1992), uses the cusp ion dispersion signatures to calculate the variation of reconnection rate over an interval of about 15 minutes prior to a cusp pass by a low-altitude spacecraft.

\section{Reconnection}

\section{$(3-\mathrm{i})$}

\section{Observations}

The magnetopause stress-balance test, revealing convecting field lines which thread the boundary via a rotational discontinuity (RD), has recently been applied by a number of authors (Gosling et al., 1990b; 1991; Paschmann et al., 1990; 1993; Sonnerup et al., 1990; Sanchez et al., 1990; Sanchez and Siscoe, 1990; Maynard et al., 1991; Smith and Rodgers, 1991). In particular, Sonnerup et al. (1990) considerably advanced the method by allowing for boundary motions and the acceleration of field lines along the magnetopause. The only problematic result was presented by Fuselier et al. (1993) who found that the mass conservation law for an ideal MHD, time-stationary, 1-dimensional RD (as assumed by the stress balance test) did not appear to hold. Essentially their result is the same as that by Paschmann et al. (1986) who invoked some $\mathrm{O}^{+}$ions in the low-latitude boundary layer (LLBL) to make mass conservation apply. The AMPTE-CCE observations of Fuselier et al. 
did not find these $\mathrm{O}^{+}$ions. The solution may rest with the time resolution of the CCE data it is important in stress test applications that all relevant, and only relevant, particles are included. However, if this is not the cause, one of the assumptions routinely applied in the stress test (i.e. that the RD is ideal - MHD, time-stationary, and one-dimensional) must be invalid. The possible implications of this are not yet understood.

On the other hand, a major success of the theory based on an ideal-MHD RD was the prediction of D-shaped ion velocity distributions of the injected magnetosheath plasma in the accelerated flows. These had been predicted as long ago as 1982 by Cowley and have now been detected using the ISEE-1 (Gosling et al., 1990a), AMPTE-UKS (Smith and Rodgers, 1991) and AMPTE-CCE (Fuselier et al., 1991) satellites. They were also generated by the MHD and hybrid simulations of Lin and Lee (1993). The mass-resolving CCE data of Fuselier et al. (1991) showed that the incident, reflected and transmitted populations from both the magnetosphere and magnetosheath were as predicted by Cowley, on both sides of the boundary. In addition, the low-velocity cut-off of the D-shaped injected distribution was shown by Smith and Rodgers (1991) to be the de-Hoffman Teller frame velocity, as derived from the stress balance test, again in accordance with the theory. The field-parallel ions of these D-shaped distributions were identified in the ionosphere by Newell and Meng (1991) and Woch and Lundin (1992a), in accordance with the results of Rieff et al. (1977) and Hill and Reiff (1977). Woch and Lundin showed the accelerated ions were on the equatorward/poleward edges of the "cusp" precipitation for southward/northward IMF, respectively, as expected for dayside/lobe magnetopause reconnection.

From regression analysis, Scurry and Russell (1991) showed magnetopause reconnection rate was influenced by solar wind Mach number and dynamic pressure (as well as by IMF strength and orientation). From cusp ion dispersion jumps, Lockwood and Smith (1992; 1994) and Lockwood et al. (1993b) showed that the reconnection sometimes takes place at one MLT exclusively in a series of pulses (about $1 \mathrm{~min}$ long and $5 \mathrm{~min}$. apart). It should be noted, however, that this situation does not always apply: for the low altitude case modelled by Onsager et al. (1993), the method of Lockwood and Smith reveals continuous and more steady reconnection (rate fluctuations are smaller than a factor of about 2) for about $12 \mathrm{~min}$. (Lockwood and Smith, 1994).

\section{(3-ii) Reconnection Simulations and Theory}

A large number of simulations of reconnection phenomena, both at the magnetopause and in the magnetotail, were carried out with various causes of resistivity in the diffusion region. Birn (1992b) simulated northward-IMF lobe reconnection; Shi et al. (1991) demonstrated how the number of X lines may depend on Reynolds number; Ding and Lee (1991) investigated oscillations between single and multi-X line reconnection; Cao and Kan (1991) and Ding et al (1992a) discussed magnetopause tearing mode and effects of plasma $\beta$, which were also simulated using a hybrid code by Hesse and Winkse (1993); the growth and stabilisation of tearing mode was investigated by Lakhina (1993), Burkhart et al. (1992) and Pritchett et al. (1991). Yan et al. (1992) simulated fast reconnection with small shear angles and Ugai (1991) carried out simulations of 3-dimensional reconnection.

Global MHD models were also employed to study magnetopause reconnection. Fedder et al (1991) found that the voltage along the X-line, arising from the 'numerical resistivity' did not depend on the model grid size employed, but did depend on the boundary conditions. In 
particular, these authors found an approximate $\sin (\Theta / 2)$ dependence of the voltage on the clock angle of the IMF, $\theta$. The reconnection was subsolar and "component" in nature, although at some $\Theta$ a hybrid of "anti-parallel" and "separator line" reconnection was found.

A cautionary point about reconnection simulations was made by Priest and Forbes (1992b), who showed theoretically how fast reconnection occurs for a number of sets of boundary conditions. Those simulations which fail to find fast reconnection use parameter regimes which do not fall within one of those sets of boundary conditions. Priest and Forbes (1992a) predict 'flipping' and no nulls for 3-dimensional reconnection. The need for 3-dimensional theory in the magnetotail was stressed by Schindler (1992). Hoshino (1991) presented a theory whereby the lower hybrid drift instability was a cause of reconnection resistivity. Lyons and Pridmore-Brown (1992) derived a theory of 'reverse reconnection', such that closed field lines can be re-opened in the tail.

A major advance was the development of an analytic theory of non-steady Petschek reconnection by Semenov and co-workers, based on the work of Pudovkin and Semenov (Yerkayev et al., 1991; Semenov et al., 1991a; 1991b; 1992a; 1992b; Semenov and Lebedeva, 1991; Rijnbeek et al., 1991). This work is important in two respects. It supports the ideas put forward by Southwood et al. (1988) and gives a greater physical insight into the simulation results of Scholer $(1988 ; 1989)$. They show how the characteristic signature of flux transfer events (FTEs) can be produced by a burst of enhanced magnetopause reconnection (over a background level) which broadens the reconnection layer. This signature surrounds a patch of enhanced boundary-normal magnetic field where the tangential electric field is proportionally increased, such that the field line velocity along the magnetopause (the de-Hoffman Teller frame velocity) is, to a good approximation, independent of reconnection rate. The second point of importance is that the magnetopause returns to the steady Petschek form if the reconnection rate is constant: this is therefore just one limit of the general behaviour. Some causes of reconnection rate variations were suggested by Lakhina (1992) and Burkhart et al. (1991).

The effects of reconnection on convection will be discussed extensively in the subsequent sections of this review. In addition, Section 6 (on substorms) will discuss its effects on the magnetic topology of the geomagnetic tail. Magnetopause reconnection also has a major effect on dayside magnetic topology. If there is little or no open flux threading the dayside magnetopause (by which one means, in this context, sunward of about $\mathrm{X}=-30$ Earth Radii, $\mathrm{R}_{\mathrm{E}}$ ) then the entire dayside magnetopause will map to a point-like cusp, as is the case for the Tsyganenko magnetic field models, as employed by Stasiewicz (1992) giving a 'teardrop' polar cap (Birn et al., 1991; Elphinstone et al., 1990; 1991). This situation would require a prolonged period with reconnection at neither the dayside nor lobe (in the hemisphere considered) magnetopause, such that the open field lines are swept antisunward and there is no boundary-normal field sunward of $X \approx-30 R_{E}$ (Lockwood, 1991d). Crooker et al. (1991b) have modelled the effect of reconnection producing newly-opened flux (that threads the boundary at $X \geq-30 R_{E}$ ) using the model of Toffelleto and Hill (1989). They show that the local time extent of the cusp increases as the cusp is 'opened' by the addition of newly-opened flux to the polar cap. Similar discussions were presented by Mal'kov and Sergeev (1991).

On the location of the reconnection X lines, Gonzales (1991) and Crooker et al., (1991a) debated the location of that in the dayside magnetopause, and Macek and Cowley (1992) showed a steady state tail $X$ line would be beyond $X=-200 R_{E}$. 


\section{Viscous-Like Mechanisms and the Low-Latitude Boundary Layer (LLBL)}

The question of how the LLBL forms, with magnetosheath-like plasma on northward-pointing (seemingly closed) field lines, is likely to be closely related to the process which drives closed field lines antisunward (viscous-like interaction). Hence they are treated together in this section.

\section{(4-i) Impulsive Penetration}

One process which aims to explain both the mass and momentum transfer onto closed field lines is "impulsive penetration". Interesting simulation results were presented by Ma et al. (1991). Using a 2-dimensional MHD code with anomalous resistivity arising from a third order diffusion term, these authors investigated the effect of any high density filaments in the magnetosheath impacting upon the magnetopause, were such structures to survive the shock and sheath traversal. They found that if the additional momentum was high enough and the internal and external fields were well aligned, the filament could penetrate the magnetopause because reconnection occurs behind the embedding filament, as proposed by Schindler (1979). This reconnection gives rise to some mixing of sheath and magnetosphere plasmas. However, if the additional momentum were too small, or the fields not well aligned, the compression of the internal field component transverse to the filament repulsed the filament, in accordance with ideal MHD. For the observed range of magnetosheath parameters, the repulsion took place unless the fields were aligned to within about $5^{\circ}$.

Some fascinating observations by the Viking satellite of double injections onto one geomagnetic field line were presented by Woch and Lundin $(1991 ; 1992 b)$. The authors interpret these as two impulsive penetration events on to the same field line. Certainly, they are not easily reconciled with the usual injection-by-reconnection scenario, in which magnetosheath plasma streams continuously across the boundary at all times between the field line being opened on the dayside and being closed in the tail (Reiff et al., 1977; 1978; Hill and Reiff, 1977; Cowley et al., 1991a; Lockwood and Smith, 1992).

Heikkila's (1982) mechanism for impulsive penetration was criticised by Owen and Cowley (1991; 1992) as violating Faraday's Law. This conclusion was supported by Roth (1992), but rejected by Heikkila (1992).

\section{(4-ii) Kelvin-Helmholtz (K-H) Waves}

There was much interest in explaining travelling convection vortices (TCVs - See Section 9) and their associated auroral transients as ionospheric signatures of the K-H waves on the magnetopause (Wei and Lee, 1993; Lee and Wei, 1993; Lotko and Shen, 1991; Schumilov et al., 1991; Kerkayev, 1991; Mezentsev, 1991). Rajaram et al. (1991) found that the magnetopause can by K-H unstable, even very close to the subsolar point. Mishin (1993) suggested that K-H waves may be triggered by solar wind dynamic pressure pulses and Miura (1992) calculated that the momentum transfer to the LLBL is low, but may be increased if $\mathrm{K}-\mathrm{H}$ vortices coalesce. 


\section{(4-iii) Other Viscous-Like Mechanisms}

Southwood and Kivelson $(1993 \mathrm{a} ; \mathrm{b})$ have shown that TCV events are drivers of convection. As a TCV moves through a given region of the ionosphere, the plasma is not quite returned to its original location but there is some nett motion in the direction of the phase motion of the filamentary field aligned currents giving the TCV. Given that the theory of Kivelson and Southwood (1991) predicts that TCVs (of opposite polarity of the leading field-aligned current) are generated by both magnetopause compressions and rarifactions, this means that solar wind buffeting by both solar wind dynamic pressure increases and decreases will cause antisunward convection of closed field lines in the LLBL. Other viscous-like (i.e. non-reconnection) processes suggested were 'gyroviscous merging' (Stasiewicz, 1991); 'pressure gradient forcing' (Samokhin 1992) and diffusion driven by the lower hybrid instability (Treumann et al., 1991).

The need for some other viscous-like process was clearly demonstrated by Owen and Slavin (1992) who applied the stress balance condition in the tail current sheet to the slowly antisunward-convecting, northward-pointing fields of the 'slow plasma sheet' (Richardson et al., 1989) as seen near the flanks of the magnetosphere at $\mathrm{X}=235 \mathrm{R}_{\mathrm{E}}$ by the ISEE- 3 spacecraft. They conclude that about $6 \%$ of the observed magnetosheath momentum flux must be transferred across the magnetopause. From the observed mass of magnetosheath-like plasma, anomalous mass transport across the boundary can account for transfer of less than $1 \%$ of the sheath momentum flux. Furthermore, Owen and Slavin's calculations reveal that the K-H instability can account for only $1-2 \%$, consistent with the results of Miura (1992). Hence stress balance of closed field lines on the flank of the tail indicates that neither $\mathrm{K}-\mathrm{H}$ waves nor anomalous mass transport are adequate viscous-like mechanisms.

\section{(4-iv) LLBL Formation}

The observations of the Cowley-D ion velocity distributions demonstrate the existence of an LLBL on open field lines at the dayside magnetopause (See Section 3). Usually the accelerated ions stream away from the subsolar point (Gosling et al., 1990b) revealing a low-latitude reconnection site. However, for northward IMF, Paschmann et al. (1993) report streams towards the subsolar point, consistent with reconnection on the edge of one tail lobe, generating an 'over-draped lobe' feature (Crooker, 1992). Other observations do indicate a closed LLBL exists on the flanks of the magnetosphere (Traver et al., 1991). However, Onsager et al. (1994) have recently shown how particle distributions which apparently indicate closed field lines can easily exist on open field lines, due to a combination of magnetic bottle and ion time-of-flight effects. Hence the existence of an open LLBL has been clearly established (Section 3-1), but the evidence for a closed LLBL is not yet conclusive.

The formation of an open LLBL is easily understood in terms of magnetosheath particles streaming into, and magnetospheric particles streaming out of, the magnetosphere. This is convolved with ion time-of-flight effects as the newly-opened field lines evolve over the magnetopause. The formation of a closed LLBL is less easily understood. Nishida (1991) proposed that field lines are successively opened and then re-closed by patchy localised reconnection, allowing entry of sheath particles onto closed field lines. A similar concept for populating the LLBL was put forward by Song and Russell (1992), but the field lines were 
re-closed by lobe reconnection in both hemispheres; however, this seems unlikely because it requires simultaneous reconnection at both lobes of the same field line.

The origin of structures in the LLBL was also debated, with Sckopke (1991) arguing that they cannot be explained as magnetopause surface waves, as suggested by Sibeck (1990).

\section{(4-v) Voltage Across the LLBL}

Several authors argued that the voltage across the LLBL could be considerable (FBrster et al., 1991; Rezenhov, 1991, Lennartson, 1992). However, this was not found to be the case by Hapgood and Lockwood (1993), using the 'transition parameter' developed by Hapgood and Bryant (1992). Hapgood and Bryant showed that the electron density and temperature ordered the complex time sequences of multiple and partial LLBL crossings (caused by boundary motions). The method orders the dayside particle characteristics observed by AMPTE-UKS extremely well and the magnetic field with only slightly greater scatter. In particular it separates the LLBL into an anti-sunward-flowing outer part and a (weakly) sunward flowing inner part. Using arguments to limit the total spatial scale of the LLBL, Hapgood and Lockwood estimate the voltage across the antisunward-flowing LLBL was less than $5 \mathrm{kV}$.

This flow structure and voltage is very similar to that observed at low altitudes by Newell et al. (1991b), using DMSP satellite and Sondrestromfjord radar data. These authors identify the LLBL signature in the ionosphere by using the ion and electron precipitation characteristics seen by DMSP and comparing them to the ISEE data from the magnetopause. Several authors note that the situation may be more complex than implied by the results of Newell at al. (1991b) and Hapgood and Lockwood (1992). For example, de la Beaujardiere et al.,1993) point out that the convection reversal boundary in the ionosphere can lie either poleward or equatorward of the LLBL signature (defined in the same manner) not just within it. Furthermore, Burke et al. (1993) report difficulties in explaining the observed convection for the particle definitions adopted by Newell et al. However, there may be no conflict with the Akebono results presented by Nishida et al. (1993), if the part of their 'circumpolar ion precipitation' (CPIP) seen convecting sunward is what Newell et al. term the 'Traditional BPS' and that part of the CPIP they observe near noon to flow antisunward is what Newell et al. term the LLBL. However, there are problems with the interpretation of ionospheric precipitations. Firstly no distinction between closed and open LLBL was made by Newell et al. and secondly, as pointed out by Lockwood and Smith (1993), ion time of flight effects on convecting field lines mean that magnetosheath ions seen at one point in the ionosphere have widely varying times-of-flight and hence widely varying points of injection at the magnetopause. Hence identification of magnetospheric regions using ion spectra is misleading and maps of ionospheric precipitation are not maps of magnetospheric regions as suggested by Newell and Meng (1992). Inspection of the occurrence plots presented by these authors shows both the 'LLBL' and 'mantle' precipitations cover almost the same MLT extent between about 9 and 15 MLT where convection is broadly poleward. This is as one would predict for an open LLBL. That the ionospheric precipitation termed 'LLBL' or 'cleft' may be mainly on open field lines is supported by observations by Taguchi et al. (1993) because the $B_{y}$-dependent field-aligned currents bound both the cusp and the cleft regions. This means that cleft field lines (after an Alfven wave travel time) are exposed to the $\mathbf{B}_{\mathbf{y}}$-dependent tension force and hence are newly-opened field lines. The evolution of the precipitation on newly-opened field lines from 'open LLBL/cleft' to 'cusp' to 'mantle' to 'polar rain' was also 
inferred from EISCAT-DMSP observations of transient dayside events by Lockwood et al. (1993b) (See Section 9).

\section{Magnetosphere-Ionosphere Coupling}

The theory of magnetosphere-ionosphere coupling made some significant advances in the review period, both with a highly complex steady-state theory and a straightforward description of non-steady state behaviour.

Siscoe et al., (1991) presented a steady-state synthesis of the voltage source of the reconnection-driven high-latitude boundary layer with the viscously-driven current source of the LLBL. The latter is understood using the LLBL-ionosphere coupling theory of Lotko et al. (1987) in which current flows across the LLBL, such that the $I \times B$ force balances viscous forcing. Siscoe et al. show how this reconfigures the polar cap current circuit, giving distributed Region 1 currents on closed field lines (instead of current sheets at the open-closed field line boundary in the reconnection-only model). The problem is then to self-consistently solve the ionospheric Ohm's law, for these separate voltage and current sources. Siscoe et al. achieve this for steady state conditions. The model predicts just $3 \mathrm{kV}$ of voltage across the LLBL (See Section 4-iv), and reproduces the behaviour of the relationship of the convection reversal boundary to the open-closed field line boundary. This work was subsequently extended by Siscoe and Maynard (1991) who added the Region 2 currents using the model of Vasyliunas (1976) to reproduce average field-aligned current and convection patterns.

The Rice model of the Region 2 currents was merged with high-latitude empirical convection patterns by Wolf et al. (1991). Pudovkin and Zakharov (1992) generated a self consistent model magnetosphere-ionosphere coupling which they used to study the effects of the spatial distribution of ionospheric conductivities.

The principles of momentum and energy transfer from the magnetosphere to the ionosphere were reviewed by Cowley (1991). Sometimes this ideal-MHD description is locally violated by field-parallel electric fields, the current-voltage relationship for which was investigated by Lu et al., (1991) and Ganguly et al. (1993).

Many studies applied, either implicitly or explicitly, the steady-state limit by mapping field-perpendicular electric fields down magnetic field lines using a $\mathrm{B}^{-1 / 2}$ relationship. (Denisenko et al., 1992; Pivarov, 1993; Belenkaya et al., 1993; Maynard et al., 1991). In fact, Weimer and Gurnett (1993), using averaged large electric fields observed at a variety of altitudes by the DE-1 satellite, found this $\mathrm{B}^{-1 / 2}$ mapping did not hold and they invoked electrostatic field-parallel electric fields to explain their result. However, in substorm growth phases induction effects cause the ionospheric fields to be smaller than the mapped magnetospheric values. A clear example with this was presented by Maynard et al. (1991) who found a magnetopause electric field from the stress balance test which would map to an unrealistic $10 \mathrm{~km} \mathrm{~s}^{-1}$ in the ionosphere, were steady state to apply but who again invoked electrostatic field-aligned electric fields. Weimer (1993) did invoke induction effects in considering substorm time scales.

Induction effects which decouple magnetosphere and ionosphere convection were discussed, in different terms, by Pudovkin et al. (1991), Sanchez et al. (1991), Lockwood et al. (1990) 
and Lockwood and Cowley (1992). Pudovkin et al. divided reconnection voltages into 'potential' and 'vortex' components, Sanchez et al. used an inductive circuit analogy, Lockwood et al. discussed curl E and Faraday's law in its differential form and Lockwood and Cowley employed Faraday loops and the integral form of the induction law. However, these different formalisms all produce the same conclusions. If we consider any Faraday loop between the magnetopause and the ionsophere, the voltage along the magnetopause segment will differ from that in the ionosphere by the rate at which the flux which threads the Faraday loop grows. Hence during substorm growth phases the growth of tail lobe flux means that the voltage across the high-latitude boundary layer exceeds that across its ionospheric footprint (i.e. the transpolar voltage). Naturally, at a later phase of the substorm cycle the lobe flux decays and the ionospheric transpolar voltage exceeds that across the HLBL. (At this point, this section is deliberately vague about during which phase of the substorm cycle open flux is destroyed: this is because this is one of the dominant issues of this review and is discussed in full in the next section). Only when averaged over several substorm cycles (one is not sufficient because it is unlikely that one substorm will return the magnetosphere to exactly the same state as it was at the start of the growth phase) are these two voltages equal, such that the motional solar wind electric field maps down field lines (as $\mathrm{B}^{-1 / 2}$ ) into the ionosphere. Note that these induction effects in no way invoke electrostatic field-parallel electric fields.

If the steady-state or time-averaged concepts of electric field mapping cannot be applied on time scales less than several substorm cycles, a new paradigm for understanding how flow is excited on these shorter time scales is required. This was formulated by Cowley and Lockwood (1992), based on the EISCAT-AMPTE data concerning the response of dayside flow to changes in the magnetic shear across the magnetopause (Lockwood et al., 1986, 1990; Todd et al., 1988; Etemadi et al., 1988) and on the SABRE-AMPTE results and discussion given by Freeman and Southwood (1988). The concept introduced was that of zero-flow equilibrium configurations of the magnetosphere-ionosphere system, for a given amount of open flux. These are idealised states, given that in practice some source of flow (eg. viscous interaction, lobe reconnection) are always present. However, recent studies using the AMIE technique (Knipp et al., 1993) show strong sunward convection in the polar cap of one hemisphere, (revealing open flux is present) with, simultaneously, a virtually stagnant ionosphere in the other polar cap (despite the fact that it too must have such open flux even if it threads the plasma sheet). These results show that the zero-flow equilibria are not such an idealised concept as one may initially expect. The equilibria are disturbed by the generation or destruction of open flux, and flow can be understood, using the concepts of polar cap boundary motion introduced by Siscoe and Huang (1985) (also called the expanding/contracting polar cap convection model), as the system tending towards equilibrium with the new amount of open flux.

Speaking personally, this agrees with reviewer McPherron and Rostoker (1993) that these induction effects were what Goertz et al. (1993) had effectively introduced to enable prediction of the $A_{E}$ indices from solar wind/IMF input parameters. Chris Goertz himself provisionally agreed with this idea when he and I discussed his paper at IAGA, Vienna two years ago. It is only a very small part of our loss, as a community, that we are robbed of a full and proper discussion and development of their paper. 


\section{Substorms}

A huge amount of literature in this review period is devoted to the one single question: "where does substorm onset occur relative to the open/closed field line boundary?". In the opinion of this reviewer, the evidence that onset occurs close to the Earth ( $\left.X \approx-8 R_{E}\right)$, and not at a Near-Earth Neutral Line (NENL) is now overwhelming. There remains just one observational fact that needs to be reconciled with this new view - namely that the tail lobe field strength is seen to start to decay at onset.

\section{(6-i) The Location of Onset}

The evidence comes from a wide variety of arguments. Onset always occurs on the pre-existing auroral oval which many have long argued was equatorward of the open/closed field line boundary (See Feldstein and Galperin, 1993, Galperin and Feldstein, 1991). These arguments frequently made use of Tsyganenko magnetic field models which should be valid so close to the Earth (Elphinstone et al., 1991; Rostoker and Sknone, 1993; Feldstein and Elphinstone, 1992; Zwolakowska and Popielowska, 1992). The new concepts are most easily visualised in terms of the 'double oval' configurations seen by the Viking UV-imager in substorm recovery phases (Elphinstone and Hearn, 1993; Murphree and Cogger, 1992; Murphree et al., 1993). These authors identify the location of the more poleward arc in the earlier substorm phases as a boundary between patchy, weak UV emission (which seems to be on closed field lines) and the region of virtually no UV emission (which they identify as open flux). In substorms, onset is on the pre-existing oval and spreads poleward, reaching the inferred open/closed boundary at the start of the recovery phase (whereupon that boundary becomes more visible, giving the double oval configuration). This view is very much supported by the comparisons of DMSP satellite data with optical observations by Lopez at al. (1992) and by the field-aligned currents seen by AMPTE-CCE in the expansion phase (Lopez et al., 1991). These observations support the idea of a near-Earth disruption of the cross-tail current, driving the substorm current wedge, as advanced by Liu et al. (1991, 1992). The resulting depolarisation is then seen to expand tailward (Jacquey et al., 1993; Ohtani et al., 1992a;b) as the aurora expands poleward (Lopez, 1993; Lopez et al., 1993). A completely independent piece of evidence was provided by Samson et al. (1992a;b) who inferred closed, even dipole-like field lines poleward of optical onset signatures, using field line resonance phenomena.

Possibly the most graphic demonstration of this development was presented by Baker et al., (1993b), from their study of the CDAW-9 interval. The method for stretching the tail in the Tsyganenko model, as developed by Pulkkinen (1991) and Pulkkinen et al. (1991a;b), was used to model the magnetic field configuration changes seen by spacecraft at a variety of tail locations during a growth phase. The highly modified model at the end of this growth phase was then used to map UV images of the onset from DE-1 and Viking into the tail neutral sheet. Despite their differences in imaging technique, the two satellites, observing in opposite hemispheres, gave roughly the same source region in the tail. Inspection of the higher time resolution Viking images then reveals onset was just tailward of geostationary orbit and spread both longitudinally and tailward. 
The view that onset was close in to the Earth $\left(X \approx-8 R_{E}\right)$ gained wide acceptance at the ICS-1 meeting on substorms in Kiruna in March 1992 - indeed this consensus view was part of what became known as "The strong Kiruna conjecture" (Kennel, 1992; Siscoe, 1993). A number of studies did, however, remind us about the variety of substorm behaviour (despite the set of common, repeatable features), for example there was evidence that weaker substorms did not originate so close to the Earth (Pulkkinen et al., 1991a; Kozelova, 1991; 1993).

The location of onset and current disruption so close to the Earth is not, in itself, a fundamental finding; however, when taken with surveys of the mid-tail region by the AMPTE-IRM satellite, the new findings call for a major revision of the NENL model which had become a standard paradigm of substorm research. Current disruption was always an important part of the NENL model, explaining the observed current wedge features, but that disruption was envisaged as taking place at the NENL. The problem is that the statistical surveys of the AMPTE-IRM data show that reconnection takes place Earthward of $X \approx-19 R_{E}$ only very rarely (Baumjohann et al., 1989; 1991; 1992). Other studies of ion streams also place the NENL at $\mathrm{X} \leq-20 \mathrm{R}_{\mathrm{E}}$ (eg. Kettman et al., 1993). Hence, the 'traditional' NENL model cannot explain onset occurring so close to the Earth.

\section{(6-ii) Current Disruption (CD) Models}

The evidence outlined in the preceding section has spawned a new class of substorm model called current disruption (CD) models, in which the near-Earth cross tail current is diverted through the ionosphere in the current wedge. This current disruption then spreads tailward, turning into a reconnection $X$-line at $X \approx-20 R_{E}$ (Lui, 1991b, Cowley, 1992). There are various proposed causes of this current disruption including: the cross-field current instability (Liu, 1991a); the ballooning instability at the near-Earth edge of the plasma sheet (Pu et al., 1992; Roux et al., 1991; Ivanov et al., 1992; Ulland et al., 1993). (On the other hand, Lee and Wolf (1992) conclude that the ballooning instability will not radically alter the tail configuration). Antonova (1993) suggests a localised electrostatic instability and Daglis et al. (1992) suggest an ionospheric contribution.

Ohtani et al. (1992b) suggest that there are two types of current disruption onset, namely spreading and explosive. The latter may be more akin to energetic particle injections at geosynchronous orbit which do not appear to show spreading in MLT.

\section{(6-iii) Near-Earth Neutral Line (NENL) Model}

The major success of the NENL model is the prediction of plasmoids and their lobe signatures, travelling compression regions (TCRs), moving down the far tail after each substorm. There was much work on plasmoids during the review period. From two-spacecraft observations, Moldwin and Hughes (1992a) showed plasmoids were stable structures, possibly flux ropes rather than magnetic islands because of the large internal $\mathrm{B}_{\mathrm{y}}$ field component (Moldwin and Hughes, 1991; 1992b;c). It was found that the number of plasmoids depends upon the criteria used to define the signatures (Moldwin and Hughes, 1992c, 1993), but despite this subjective element to their identification, all plasmoids can be associated with a substorm. The converse, that each substorm yields a plasmoid, was found to be true by Slavin et al. (1992) who showed that in a uniquely continuous period of 36 hours of ISEE-3 tail observations, each of 14 substorms generated a plasmoid/TCR. 
The formation of plasmoids in MHD models of tail behaviour was clearly demonstrated in a number of studies (Birn and Hesse, 1991a; Hesse and Birn, 1991a;b;c; 1992 a;b). Global MHD models also reproduce this behaviour: Walker et al., $(1992 ; 1993)$ found that a NENL forms $\sim 1$ hour after a southward turning of the IMF and at $X \approx-19 R_{E}$.

The evidence of tail plasmoids/TCRs calls for a NENL, and hence current disruption (CD) models invoke a NENL forming, but only after the disruption has spread down the tail. The difference is that in a CD model the current disruption gives rise to the NENL, not the other way round. If the evidence in favour of the $\mathrm{CD}$ model is the answer to the question "where does onset occur?", that in favour of the NENL model tends to be in terms of "when does a NENL form?" and "when does it begin to reconnect open flux? (i.e. when is the plasmoid magnetically pinched off from the Earth?)". In the classical NENL model these two times are considered to be very close together and hence the observations that the tail lobe field begins to decay at the time of onset are evidence supporting this model. (McPherron et al., 1993). Lin et al. (1991) conclude that ion stream directions in the first CDAW-6 substorm are consistent with a slightly modified NENL model, in that they invoke small magnetic tearing islands near the X-line which they believe to pass over the ISEE-1 and - 2 satellites at $\mathrm{X}=-15 \mathrm{R}_{\mathrm{E}}$. However, there are difficulties with this interpretation as the reversal from tailward to earthward ion streams is not accompanied by a reversal in the $\mathrm{B}_{\mathrm{z}}$ field component from south to northward, as would be expected for a tailward motion of the NENL over the satellite. Rather the multiple nature of the reversal in stream direction and the fact that tailward streams briefly re-appear sometime after the proposed X-line passage imply that both a NENL and a distant X-line are active on either side of the satellite and the plasmoid is not yet pinched off.

This idea also arises from a number of other studies. The results of Slavin et al., (1992), discussed earlier, show a range of delays between substorm onset and observation of a plasmoid/TCR of about $0-30 \mathrm{~min}$. Slavin et al. attribute this to the inaccuracies of onset indicators. However, this is true for all 4 indicators they employed (AKR, Pi2, AL index, and electron injection at geosynchronous orbit) and this suggests that the plasmoid may not always pinch off as quickly as the classical NENL model requires in order for it to explain the decay of tail lobe field (McPherron et al., 1993).

An extremely significant result in this respect is that presented by Owen and Slavin (1992) who showed that Earthward of $\mathrm{X}=-100 \mathrm{R}_{\mathrm{E}}$ most plasmoids and TCRs are bounded by earthward-streaming ions or bi-directional ion streams, whereas tailward of this point no Earthward streams were detected. This result clearly indicates that plasmoids/TCRs move down the tail before they are pinched off by the NENL. This is entirely possible under the action of pressure gradients and dynamic pressure of outflow particles, as discussed by Scholer and Hautz (1991). The plasmoid therefore moves tailward despite overdraped closed flux, rather than because of the magnetic slingshot of flux newly returned to the IMF (as in the classical NENL model).

This result agrees well with ionospheric observations that the total amount of open flux does not start to decay at onset, but rather that open flux is mainly destroyed in the recovery phase. This was deduced by Akasofu et al. (1992) from the inferred size of the polar rain precipitation region and by Lockwood and Cowley (1992); Förster et. (1991), Mishin et al., (1992a;b) and Saifudinova et al. (1992) from convection patterns derived by magnetogram 
inversion techniques. The same result is apparent in the superposed epoch studies of the diameter of the 'convection polar cap' given by Weimer et al. (1992) (see section 7).

\section{6-iv) Synthesis of CD and NENL Models}

From the previous two sub-sections there is a clear need for the 'classical' NENL model to be modified to allow for where onset occurs and when open flux is destroyed. On the other hand, plasmoids clearly exist, as do ion streams emanating from both Near-Earth and distant reconnection neutral lines.

One possible solution to this paradox are the "action-at-a-distance" modified NENL models. These are, in essence, NENL models in that the NENL still causes the CD and not the other way round. Examples of this include the 'flux pile-up' concept of Bim and Hesse (1991b) who use an MHD model to show that depolarisation can begin near $\mathrm{X}=-8 \mathrm{R}_{\mathrm{E}}$ and spread tailward as flux recently reconnected by a NENL near $X=-20 R_{E}$ moves rapidly Earthward and piles up at the inner edge of the plasma sheet. Another such model is that proposed by Baker et al. (1993) who postulate that cross-tail current is diverted Earthward by the NENL (for which the reconnection rate is initially low). The diverted current then thins the sheet at $\mathrm{X} \sim-8 \mathrm{R}_{\mathrm{E}}$, giving chaotic particle orbits and precipitation (Pulkkinen et al., 1991a; 1991b). This model predicts that the electrojet will be poleward of the optical signatures which Baker et al., argue to be the case for the CDAW-9 event.

The concept by Baker and McPheron (1990) that the NENL voltage increases dramatically when the low $\beta$ plasma of the lobe reaches it (i.e. after the plasmoid is pinched off) can be valid in either NENL or CD models. However CD models call for this rise in reconnection rate to be at the onset of the recovery phase and nothing to do with start and the expansion phase.

Personally, this reviewer is attracted to the idea of a synthesis of CD and NENL models proposed by Reeves et al. (1992) and Reeves (1993) in which CD and NENL formation are responses of different tail regions to the same stress (i.e. excess lobe flux), rather than CD directly causing the NENL or vice-versa. In the Reeves et al. model, the stress in the inner region is generated by the NENL, but the timing of the onset of reconnection signatures, relative to the timing of onset of ionospheric signatures is considered by some to be controversial. However, Reeves et al. do clearly demonstrate that in the CDAW-7 substorm one injection occurs before the plasmoid is pinched off (as determined from ISEE data by Kettman et al., 1990) whereas the other two occur after this time.

However, two important questions need to be answered before the synthesis views can be fully accepted. Firstly, if tail lobe flux does not decay in the expansion phase, why do the tail lobe field strengths start to decrease at onset (McPherron et al., 1993)? Two ways that lobe area may increase are by tail flaring and/or plasma sheet collapse which may both be associated with the cross-tail current disruption. However, as yet nobody has provided a satisfactory explanation. This also raises the question of energy storage. Ultimately the tail lobe field is the source of the energy to power substorms. An increase in lobe area (without loss of flux) will release stored energy because energy density is proportional to $\mathrm{B}^{2}$. Alternatively, is the energy deposited in the early expansion phase (observed signatures are dominated by electrojet Hall currents and luminosity), simply supplied by the plasma sheet, rather than by the lobe? Could the major energy deposition be by Joule heating in the 
recovery phase? A generalisation of the energy budget during the various substorm phases (Mavramicalaki and Belehaki, 1993) is thus called for.

\section{(6-v) Magnetospheric Response Functions}

The question of directly-driven versus loading/unloading did not command as much attention as in previous years and much of what was written was a review nature (Baker et al., 1993a; Lui, 1993). The heat of this debate may partially have abated because of a growing realisation that the magnetospheric behaviour has aspects of both types of system. McPherron and Baker (1993) argue that IMF history and non-linearity give a spread in the delay and size of magnetospheric responses. This would appear to be supported by contrasting two separate studies reported in the review period. Farrugia et al. (1993) report substorm signatures at geosynchronous orbit (dipolarisations and injections) during an 18-hour period of steady and continuously southward IMF, caused by the passage of an interplanetary magnetic cloud over the Earth. The mean repeat period of the substorms they identified was $50 \mathrm{~min}$, with a mode of the distribution at about $35 \mathrm{~min}$. The statistics of IMF behaviour presented by Hapgood et al. (1988) show that such prolonged strongly southward IMF is an extremely rare occurrence indeed. Even under such steady forcing, the magnetosphere did not establish a steady-state convection bay but rather the convection showed a series of substorms with Earthward convection surges (dipolarisations).

On the other hand, Borovsky et al. (1993), studied a great many substorms which, due to their definition criteria, were more 'isolated' in nature with more pronounced growth phases. Because they used no special IMF selection criteria (as employed by Farrugia et al.) the IMF $\mathrm{B}_{\mathrm{z}}$ will vary much more rapidly, with roughly a $50 \%$ chance of changing polarity after about $30 \mathrm{~min}$. (Lockwood, 1991b). For this selection and substorm definition, Borovsky et al. report a mean repeat period of 2 hours in reasonable agreement with the lag yielding peak autocorrelation of the $A_{E}$ index, as found by Shan et al. (1991).

The non-linear nature of the magnetospheric response was discussed by Baker et al. (1991), Klimas et al. (1991) and Vassiliades et al. (1991). Blanchard and McPherron (1933) discussed the bi-model nature of the response. Roberts et al. (1991) and Roberts (1991) applied the concept of a low-dimensional non-linear oscillator. Another novel concept was the application of catastrophe theory to substorms by Lewis $(1991,1993)$.

\section{(6-vi) Other Aspects of Substorms}

The next section (7) deals with convection during substorms, however there are a number of papers on substorms which do not fit easily into this, or any of the previous, categories and are therefore gathered into this section.

Kidd and Rostoker (1991) studied multiple auroral surges, Rothwell et al. (1991) studied pre-breakup arcs and Koskinen et al., (1993) studied psuedobreakups. Zverev and Starkov (1991) surveyed the size of poleward auroral expansions, which was modelled numerically by Birn (1993).

Atkinson (1993) advanced the concept that substorms represented a more gradual shift from dominant magnetopause reconnection to dominant tail reconnection than is implied by the 
explosive nature of onset, and the tail lobe field changes were surveyed statistically by Nakai et a. (1991) as a function of IMF $B_{z}$ and solar wind dynamic pressure.

Huang et al. (1992) discussed plasma sheet heating in substorms and Lyons and Huang (1992) reported a plasma sheet expansion at $15-22 \mathrm{R}_{\mathrm{E}}$ during onset, which need not be inconsistent with the above discussions. Kistler et al. $(1992,1993)$ studied pressure changes in the plasma sheet during substorms. Singer et al (1993) have reviewed CRRES satellite observations of substorms and Sanchez et al. (1993b) have studied low-altitude observations of injections.

Substorms wee also reviewed by Fairfield (1992) and their relation to storms discussed by Kamide (1992). A review of low-latitude signatures and effects of substorms was made by Rostoker (1993).

\section{Convection and Substorms}

Convection is frequently viewed as the directly-driven part of the magnetospheric response onto which substorm electric fields, produced by the storage/unloading system in the expansion/recovery phase, are superposed (Baker et al., 1933a; Kamide and Richmond, 1991). However, a different view has been developed by Siscoe and Huang (1985), Moses et al. (1989), Lockwood and Freeman (1989), Lockwood (1991c) Lockwood et al., (1990) and Lockwood and Cowley (1992), namely that the electric fields of the expansion and recovery phases are an integral part of the total circulation we term convection. In this view, the flows driven by dayside reconnection (associated with polar cap expansion) give the directly-driven aspects of magnetospheric response, whereas those driven by nightside reconnection (associated with polar cap contraction) give storage/unloading aspects to the convection response. Note the importance to these ideas of the induction effects and the concept that ionospheric convection is driven by the generation and destruction of open flux (see section 5).

Relatively little is known about the behaviour of electric fields during substorms, compared to the vast amount that is known about the ionospheric Hall currents they cause (the differences between the two naturally reflect the variability of the spatial distributions of ionospheric conductivities). Freeman et al. (1992) reported SARAS - substorm associated radar auroral surges - using the bistatic VHF SABRE radar system (see also Nielsen, 1993). However, the work of Robinson (1993) shows that although the direction of flow in the surges will be approximately correct, the magnitude of the flow is likely to be erroneous. In radar flow bursts seen using the EISCAT radar by Morelli et al. (1993), weak ground magnetometer deflections were observed, but which were far from proportional to the observed electric fields. The role of the conductivity variations was discussed by Pellinen (1993) and Lysak et al. (1992).

An extremely revealing study of convection during the substorm cycle was presented by Weimer et al. (1992) who made a superposed-epoch study of transpolar voltage, $\theta_{\mathrm{pc}}$ as a function of time relative to onset, using DE-2 observations. The ratio $A_{E} / \theta_{p c}$ is depressed in the growth phase because of the enhanced convection (due to the generation of open flux), but shows very large values in the expansion phase. This strongly suggests that the expansion phase exhibits dramatic conductivity and current increases, but has much smaller effect, if any, on global electric fields and flux transport in the ionosphere. The transpolar 
voltage remains at relatively constant values in the growth and expansion phases, but decays during the recovery phase. The dawn-dusk diameter of the convection polar cap, on the other hand, increases during the growth phase, stays constant during the expansion phase and then decays during the recovery phase. These results strongly support the concept of ionospheric flow excitation by the generation and destruction of open flux (Cowley and Lockwood, 1992), but also support the idea that open flux is not destroyed (at least at any significant rate) until the recovery phase, as discussed in Section 6.

The behaviour described by Weimer et al., is broadly supported by a three-radar study of two substorms by Lester et al., (1993), in that at all three radars (viewing the nightside) the flow magnitudes increased and decreased smoothly through the substorm cycle, with no major increase at onset. However, the poleward retreat of the convection boundary did appear to begin closer to the time of onset than seen near dawn and dusk by Weimer et al. This could be interpreted as indicating earlier closure of open flux with a relatively slow return of the polar cap towards the new equilibrium configuration, or it could be the effect of a region of enhanced conductivity (which flow streamlines will tend to avoid if the magnetosphere cannot allow field-aligned currents at the conductivity gradients which bound that region).

The results do not appear to support the idea by Nakamura et al. (1993) that the substorm expands along flow streamlines.

Lester et al. also show that the convection enhancement is seen at these nightside radars some 15-30 min after the southward turning of the IMF. Indeed, the results are consistent with the expansion of the flow enhancement away from near noon seen on the dayside by the EISCAT-AMPTE observations (Lockwood et al., 1986; Etemadi et al,, 1988; Todd et al., 1988), as recently confirmed by Saunders et al. (1992) by comparisons of IMP-8 and CANOPUS magnetometer data. Direct observations of such an expansion of the enhanced electric fields were also presented by Lockwood et al. (1993c). There are a number of possible explanations of this expansion, but which is the most likely is not yet clear. The results of Lester et al. show that convection is enhanced throughout the nightside some $20 \mathrm{~min}$. before the end of the growth phase. This appears to be too early to support the magnetosphere-ionosphere coupling model, in which the current wedge field-aligned currents are enhanced by enhanced ionospheric convection (Kan, 1991; 1993a;b; Sun et al., 1991). Hesse and Birn (1991c) did, however, model how magnetosphere-ionosphere coupling effects could hasten the release of the plasmoid once a NENL has formed,

Because of induction effects (See Section 5), these ionospheric electric fields seen during substorms cannot be viewed as mapped images of convection in the magnetosphere. This is particularly clear when discussing dipolarisation where the huge convection surge in the equatorial magnetosphere, as observed by Laasko et al., (1992), Pederson et al. (1992) and Sanchez et al. (1993a), appears to have only a weak electric field signature at ionospheric altitudes (Weimer et al. 1992; Lester et al. 1993).

An extremely interesting study of field-aligned currents in substorms was presented by Chun and Russell (1991), using 180 orbits of the ISEE-1 and -2 satellites. As in the study of the corresponding ionospheric convection by Weimer et al. (1992), the data were sorted according to the phase of the substorm cycle. Major field-aligned currents (over their detection threshold) were observed in 27 of the orbits and in each of these cases the pass could be designated as during either a growth, expansion or recovery phase of a substorm. It was found that in the growth phase the total current intensity (in $\mathrm{A} \mathrm{m}^{-1}$ ) was more than twice 
as large in the Region 1 (R1) currents than in the Region 2 (R2). Noting that the R1 currents contain both the 'polar cap' and the 'auroral/ring current' loops (termed here the PC and AVRC loops), whereas the R2 are part of the A/RC loop only, this shows the dominant current loop in the growth phase to be the PC, consistent with solar wind forcing. In the expansion phase, both R1 and R2 currents are enhanced, relative to those in the growth phase, such that the difference between the two is not altered. This shows PC loop current has remained roughly constant, but the $\mathrm{A} / \mathrm{RC}$ current has roughly doubled in strength, indicating an internal magnetospheric response. Lastly, in the recovery phase the R2 (A/RC) current intensities of the expansion phase are maintained, but the difference between R1 and R2 (the PC current) has fallen to zero. These results are consistent with our general concepts of solar wind forcing in growth phases and the magnetospheric response. However, there are two highly significant points about this study. Firstly, no significant R1 nor R2 current was found which did not belong to one or other substorm phase. In other words, strong R1 and R2 currents and convection could be thought of as a substorm phenomenon and that steady-state balanced convection (a 'convection bay') was not found in this study. This supports the studies of Freeman et al. (1993) and Farrugia et al. (1993) who observed a string of substorms but no convection bay despite a very prolonged period of strongly and steadily southward IMF. The second significant feature of the Chun and Russell study is the velocity of the R1 and R2 current sheets, as determined by comparison of the ISEE-1 and ISEE-2 data. In all phases of the substorm, both R1 and R2 currents expanded equatorward. This is expected for the growth phase, but one may have expected return poleward motion in the expansion and/or recovery phase: in fact, these phases always also showed equatorward motion, albeit at lower speed. The authors suggest, therefore, that R1 and R2 currents form at the onset of the growth phase at very high latitudes and expand equatorward continuously before fading at the end of the recovery phase at lower latitudes. A new R1-R2 current pair then forms at the highest latitudes at the start of the next growth phase.

Farrugia et al. (1993) make the point that substorms continue after the IMF has retumed northward, driven by residual open flux built up in a prior period of southward IMF. Studies of such northward-IMF substorms have been made by Lester et al. (1993) and Fox et al. (1993). The study by Fox et al., discusses the possibility, raised by Lockwood (1991d) and Lockwood and Cowley (1992) that apparently viscously driven flows in the ionosphere (Burch et al. 1992) may, in fact, be driven by continuing tail reconnection after the IMF has turned northward (see also Knipp et al., 1991a;b; Lockwood and Cowley, 1991 and Crooker, 1992). Fox et al. find that the voltage of apparently viscously-driven antisunward flows (sandwiched between the lobe and auroral regions of sunward flow) peaks in magnitude when the polar cap contracts in response to substorm signatures near midnight. This clearly indicates that much of the $12.5 \mathrm{kV}$ of apparently viscous flow is actually driven by nightside reconnection and associated with polar cap contraction, as predicted by Cowley \& Lockwood (1992).

Lastly, middle- and low-latitude enhancements of electric fields associated with substorms were reported by Sastri et al. $(1992 a ; b)$ and the relationship of the sub-auroral ion drift (SAID) phenomenon to substorms was investigated by Anderson et al. (1993). 


\section{Flow Patterns and their Variations}

\section{(8-i) Convection Patterns and Transpolar Voltage}

The magnetic cloud event of January 1988 was a particularly rich source of data on the variation of ionospheric flow patterns as a function of the various quasi-steady IMF orientations, both northward and southward (Freeman et al., 1933; Cumnock et al., 1992; Knipp et al., 1993), although the magnetosphere-ionosphere system never reached a steady-state when the IMF was continuously and strongly southward (Farrugia et al., 1993). The transpolar voltage was shown by Freeman et al., (1933) to display the 'half wave rectified' dependence on IMF $B_{z}$ expected from previous studies but only in one hemisphere. In the other hemisphere, northward IMF conditions gave rise to strong 'reverse convection' (see Section 8-iv), such that opposite polarity voltages were observed and the transpolar voltage had a fully linear dependence on IMF $\mathrm{B}_{x^{*}}$. Note that this definition of transpolar voltage takes no account of where the open/closed boundary is and is based purely on the convection potential distribution.

Ahn et al. (1992) also found good correlations of transpolar voltage with IMF $\mathrm{B}_{2}$ (and other indicators of the strength of solar wind-magnetosphere coupling such as $\varepsilon$ ). They also found a good correlation with $\mathrm{A}_{\mathrm{E}}$. However, the large variation in the ratio of the two between the growth and expansion phases, as found by Weimer et al. (1992), highlights the danger of averaging over all substorm phases, in which behaviour can be radically different.

De la Beaujardiere et al. (1991a) found a winter-summer asymmetry in average transpolar voltage (but not polar cap size). Given that the mean rate of flux transfer from the dayside to the nightside must be the same in the two hemispheres, this cannot be a conductivity effect. One possibility is a lobe circulation which adds to the total antisunward flow in just one polar cap (whilst also giving some sunward flow on open field lines), and that the occurrence of this lobe circulation has a seasonal dependence.

\section{(8-ii) Flow Bursts}

Flows in the ionosphere could be made up of a variety of short-lived phenomena which contribute to flux transport, and which when averaged over long enough time scales give the nett circulation we term convection. Tristatic flow measurements in small but rapid scans of the EISCAT UHF radar demonstrate that sunward auroral convection in the ionosphere can be very bursty in nature (Williams et al., 1992). These authors have analysed the errors in the tristatic radar technique and show they are at least an order of magnitude smaller than the flow speeds in the bursts. Furthermore, the F-region ion temperature measurements are entirely independent, yet yield peaks consistent with the effect of the derived flows via ion-neutral frictional heating and E-region electron temperatures also show consistent peaks, caused by turbulent E-region heating. Hence the sunward flux transport across four points in the auroral zone takes place in a series of bursts of order 5-10 min duration. Lewis et al., (1993) have shown that these bursts can always be associated with southward IMF, but are not directly driven by the IMF. Multi-instrument and conjugate observations of one class of ionospheric flow burst have been reported by Morelli et al. (1993). 
Similarly, the sunward flow in the central plasma sheet has been found to be bursty in nature. Although induction effects make it highly unlikely that the bursts of flow in the CPS and ionosphere are directly related, the similarity in the nature of convection on short time scales is striking. As in the ionosphere, steady-state highly averaged flow concepts have been applied to the plasma sheet (Pivovarov, 1991; Donovan and Rostoker, 1991; Liu and Rostoker, 1991); however, the bursty nature of the mid-tail plasma sheet flow has been stressed by Angelopolous et al., (1992a). They report 'bursty bulk flow' events (BBF), as observed using AMPTE-IRM. These occur at all $\mathrm{A}_{\mathrm{E}}$ values and are responsible for very considerable flux transport because they are accompanied by a rise in the (positive) $\mathrm{B}_{z}$ component, as shown by a superposed epoch study. Similar events were detected by Sergeev et al., (1992) who termed them 'nightside flux transfer events'. The importance of such events was clearly demonstrated by a statistical survey by Angelopolous et al. (1992b) who showed that the high speed tail of the velocity distribution was responsible for the majority of the particle, energy and, in particular, the flux transport. Taking the whole plasma sheet, these authors found that although BBF events were present just $7 \%$ of the time, they were responsible for $44 \%$ of the Earthward particle transfer, $48 \%$ of the energy flux but $125 \%$ of the flux transfer. (This last figure can exceed $100 \%$ because there is nett antisunward transport in the periods between the BBF events). The stability of the central plasma sheet to convection has been studied by Pritchett and Coronitti $(1992 \mathrm{a} ; \mathrm{b})$ who conclude steady convection may not be possible because of the build-up of $\mathrm{B}_{\mathrm{z}}$ which chokes convection (Erickson and Wolf, 1980). That the fast flows are consistent with tail reconnection was confirmed by Nakamura et al., $(1992 ; 1993)$ who showed statistically that fast Earthward flows were accompanied by positive $B_{z}$, whereas fast tailward flows were associated with $\mathrm{B}_{z}<0$.

\section{(8-iii) IMF B , Assymetries}

There are a number of well-known $\mathrm{B}_{\mathrm{y}}$-dependent flow, field and precipitation asymmetries in the magnetosphere and ionosphere. Cowley et al. (1991b) fitted all these into one simple theoretical paradigm using a dipole-plus-uniform field model to stimulate the effect of asymmetric addition of open flux to the tail lobes (Gosling et al., 1990b). The $\mathrm{B}_{\mathrm{y}}$-dependent shift of the region of open flux was clearly demonstrated in Viking UV images by Elphinstone et al. (1990) and was also seen in convection patterns from magnetogram inversion by Mishin et al. (1992c). Other asymmetries which are well-explained are the $\mathrm{B}_{\mathrm{y}}$ component of the subsolar field, the MLT of the cusp (confirmed by Aparicio et al. 1991), the MLT of the convection 'throat' (oppositely shifted to the cusp because of the Svalgard-Mansurav effect on newly-opened field lines); and the dominant sense of the cusp field-aligned currents. The morphology of the dayside field-aligned currents (for strong $\left|\mathrm{B}_{\mathrm{y}}\right|$ conditions) is predicted by Cowley et al. to be similar to that proposed by McDairmid et al. (1978). The cusp currents are spatially contiguous with the region 1 currents on one polar cap flank although, because they are caused by the decay of the magnetic tension force (Saunders, 1989), they do not have the same physical origin as the Region 1 currents. Saunders (1992) showed this field-aligned current morphology was consistent with averaged dayside convection models (see also Israelevich and Nikolaeva, 1991). Strong support for the predictions of Cowley et al. (1991b) for large $\left|B_{y}\right|$ came from combined DMSP and Sondrestrom radar observations of field-aligned currents, flows and particle precipitation regions (de la Beaujardiere et al., 1993). For $\mathrm{B}_{\mathrm{y}} \approx 0$ cases the weaker cusp currents would be expected to lie poleward of the Region 1 currents and not be contiguous with them. 
Conjugate observations of the changes in azimuthal flow in the dayside polar cap, caused by IMF $B_{y}$ polarity changes, were demonstrated by Greenwald et al. $(1990 ; 1991)$. The evolution of the flows and the required field-aligned currents were as predicted by Cowley et al. (1992).

The effects of IMF $\mathrm{B}_{\mathrm{y}}$ on flow direction in the central polar cap were observed by Cannon et al. (1991) using a digisonde at Qannaq. Dudeney et al. (1991) reported IMF B effects in the flows in the pre-midnight sector, which might be explained by the $\mathrm{B}_{\mathrm{y}}$-dependent nightside current system proposed by Pudovkin and Zaitseva (1993).

\section{(8-iv) NB $_{2}$ Convection}

Magnetopause observations reveal reconnection at the sunward edge of the tail lobe when the IMF is northward (Gosling et al., 1991; Paschmann et al., 1990; 1993). (See also correspondence by Belenkaya, 1993 and Gosling et al., 1993). The effect of such reconnection was discussed by Crooker (1992) who considered quasi-steady and transitional (non-steady) situations with allowance for induction effects (see Section 5). Crooker made particular use of the overdraped lobe concept, which is supported by the observations of Paschmann et al. (1990; 1993) of equatorward accelerated flows on the dayside during northward IMF. This topology predicts one tail lobe may reconnect with the sheath field (in fact the summer hemisphere is favoured by the Earth's dipole tilt), while the other remains effectively stagnant (Crooker \& Rich, 1993). Exactly this situation was observed by Knipp et al., (1993) using the AMIE technique to study the January 1988 magnetic cloud event. A second prediction by Crooker which has already been verified is the transitional state when the IMF has only recently turned northward and open flux continues to be closed in the tail. As pointed out by Lockwood and Cowley (1991), this situation was observed by Knipp et al. (1991a;b), again using the AMIE technique. Ruohoniemi et al. (1993) found the decay of dayside flows following a northward turning to be consistent with the EISCAT-AMPTE observations of Todd et al. (1988). The residual nightside flow observed after the northward turning by Knipp et al. (1991a) mimicked viscous-like interaction, as discussed by Fox et al. (1993).

The AMIE technique was also used by Knipp et al. (1991a) to study the evolution of $\mathrm{NB}_{z}$ convection patterns in response to slow rotation of the IMF clock angle. Similar studies were made possible during the January 1988 magnetic cloud event (Freeman et al., 1993; Cumnock et al., 1992).

Steady-state concepts of $\mathrm{NB}_{\mathrm{z}}$ convection were used by Burch et al. (1992) and Sharber et al. (1992) to interpret flows associated with the teardrop aurora, and the relationship of the flows with observed $\mathrm{NB}_{z}$ field-aligned currents were investigated by Blomberg and Marklund (1991) (see also Zhu et al., 1991 and Nikolaeva, 1991). The flows in the central polar cap during northward IMF were observed using the digisonde technique by Crowley et al. (1992) and the effect of IMF $B_{y}$ on sunward polar cap convection was investigated by Cannon et al. (1992). 


\section{(8-v) Flows near Arcs}

The relationship of flow shears to auroral arcs was discussed by Weber et al. (1991) and Aikio et al. (1993). Valladares and Carlson (1991) found such shears near polar cap arcs which Makita et al. (1991) conclude lie on the open/closed field line boundary, as also argued by Elphinstone et al. (1990). Marklund et al., (1991) and Marklund and Blomberg (1991) observed plasma drifting through a transpolar arc, as deduced using their convection modelling technique from the Viking UV images and observed field-aligned currents (see Marklund, 1992; 1993). Zhu et al. (1993) argue that such flow through a transpolar arc is necessary if it is to be stable. Note that the concepts of Siscoe and Huang (1985) show that flow streamlines crossing a transpolar are are not inconsistent with that arc being the open/closed field line boundary (as suggested by Elphinstone et al., 1990): it is not necessary to invoke reconnection, merely a motion of an arc which is on a moving adiaroic open/closed boundary.

\section{8-vi) Mid-Latitude Electric Fields}

Seasonal and solar cycle changes in mid-latitude, and sub-auroral electric fields were studied by Buonsanto et al. (1993), using data from the Millstone Hill radar. The phenomenon of sub-auroral ion drifts (SAIDs) was investigated using satellite data by Heelis and Coley (1992), Anderson et al (1991) and Saxton and Smith (1991). Extreme convection conditions at mid-latitudes, caused by highly expanded polar caps were described by Yeh et al. (1991), Foster (1993); Buonsanto et al. (1992), Krymskiy and Fillipov (1991), Okada et al. (1993); Chen and Huang (1993) and Walker and Wong (1993).

\section{Dayside Transients}

In this review period, several suggestions emerged that transient magnetopause phenomena may play a significant role in large-scale flux transport in the magnetosphere/ionosphere system. Hence this review concludes with a brief review of these phenomena, concentrating on the arguments about their contributions to large-scale fields and flows. A key issue in dealing with any dayside transient was deciding if it was the result of a reconnection burst (i.e. a 'flux transfer event' - FTE) or of a sudden change in solar wind dynamic pressure which is thought to generate a travelling convection vortex (TCV).

\section{(9-i) Magnetopause Events}

The analytic theory of Semenov and co-workers (see Section 3-ii) confirms that bursts of reconnection will yield bipolar boundary normal field variations with enhanced field magnitudes by generating a travelling thickening of the reconnection layer (i.e. of the open LLBL). This analytic theory therefore supports previous conceptual modelling and numerical simulations showing that reconnection bursts generate magnetopause signatures of the kind first detected by Russell and Elphic (1978) and Haerendel et al. (1978). Numerical simulations showing non-steady reconnection at a single X-line generating FTE-like structures were carried out by Otto and Arent (1991), confirming the work by Scholer (1988; 1989). Such structures were also produced by time-dependent multi $X$-line simulations by Ding et al. (1991; 1992b), Wei et al. (1991) and Liu et al. (1992). An alternative explanation of these FTE signatures by Sibeck (1992), that they are produced by pressure-pulse induced 
surface waves, is based on conceptual modelling but has not yet been confirmed by either analytic theory or numerical simulations.

One FTE observation which has received much attention in terms of evaluating these two explanations is the 'crater' FTE observed on 28 October 1984 by the AMTE-UKS and -IRM satellites (Farrugia et al., 1988; Rijnbeek et al., 1987). Sibeck and Smith (1992) concluded that neither model satisfactorily explained the flows observed during this event. This does not pose a great problem for the reconnection burst model because boundary motions can be invoked. However, they cannot be added for the pressure pulse model as they are already invoked as an explanation of the FTE signature itself: adding boundary motions would alter the FTE signature. Smith and Owen (1992) showed that the ion temperature anisotropy in the event centre was different from that in the magnetosheath. This is inconsistent with Sibeck's (1992) interpretation of a brief re-entry of the satellite into the sheath caused by the boundary surface wave. Lockwood (1991b) argued Sibeck's mechanism would give tripolar, rather than bipolar boundary-normal field signatures and that, from IMF variability statistics, Sibeck's explanation of the dependence of magnetospheric FTEs on the sheath field orientation earlier/later in the same pass was exceedingly unlikely.

The question of whether FTEs are due to spontaneous or driven reconnection was raised by Lockwood and Wild (1993) who showed that the often-quoted FTE repeat period of 8-min was a mean of a highly skewed distribution, which was also inherent in the FTE statistics given by Elphic (1988). Hence they deduced that 8 minutes was not an internal oscillation period of the magnetosphere-ionosphere system. They suggested from the similarity of the distribution to that for IMF changes, that FTEs were directly driven and that the lower cut-off period of the distribution was merely dependent on the arbitrary definition used to distinguish FTE's from "B $\mathrm{n}_{\mathrm{n}}$ activity". Le et al. (1993) used a number of case studies to show that not all FTEs could be attributed to IMF $B_{z}$ fluctuations, as Lockwood and Wild had suggested. Another possibility is that solar wind dynamic pressure pulses may enhance the magnetic shear by compressing the magnetosheath and magnetospheric fields, as suggested originally by Elphic (1988). This idea was also discussed by Bol'shakova et al. (1991) and Scurry and Russell (1991) showed by regression analysis that it was valid, at least for longer time scales. This may also provide an explanation of the observations by Potemra et al. (1992) of an FTE signature observed superposed on longer-period magnetopause oscillations caused by solar wind dynamic pressure changes.

It is clear that both transient reconnection and solar wind dynamic pressure changes should cause transient events in the outer dayside magnetosphere and at the magnetopause. A step towards resolving the two may have been made by Kawano et al., (1992) who showed FTE-like events seen by AMPTE-CCE (at $\mathrm{L}=6-9.4$ ) seem to fall into 2 classes: those lasting 1.5 min or less showed a clear tendency to occur during southward IMF (and hence appear to be FTEs), whereas those lasting for more than $1.5 \mathrm{~min}$ showed only a slight bias to southward IMF (consistent with dominant pressure change effects). Hence the 1.5-min threshold does not appear to completely separate the two classes, but nevertheless is a useful first step. 


\section{(9-ii) Dayside Transients in the Ionosphere}

As at the magnetopause, it became clear that dayside ionospheric transients fell into two categories: "dayside breakup events" and "travelling convection vortices" (TCV's). The evidence that these two are the signatures of transient magnetopause reconnection and solar wind dynamic pressure changes, respectively, also grew. Jacobson et al. (1991) found differences in the morphology of the auroral transients associated with these two class of events, but the major differences were in the patterns of ionospheric plasma flow and event phase motion (Lockwood et al. 1990). The two types of event are considered separately in the following two sections.

\section{(9-iii) Dayside Auroral Breakup Events}

Much of the work revealing the structure and dynamics of these poleward-moving events was prior to the review period and has been reviewed by Sandholt et al. (1992a, 1993a) and Lockwood (1991a). Two pieces of evidence that these are caused by reconnection bursts comes from their occurrence during southward IMF and their east/west motion (often initially sunward) depending on the polarity of the IMF $\mathrm{B}_{\mathrm{y}}$ component. Eastward-moving $557.7 \mathrm{~nm}$ transients (seen by white-light cameras) under IMF $\mathrm{B}_{\mathrm{y}}<0$ had been observed from the Svalbard islands (northern hemisphere) only relatively rarely. This difference in occurrence was found not to apply to the $630 \mathrm{~nm}$ (red-line) transient events, and examples of $\mathrm{B}_{\mathrm{y}}<0$ events were presented by Sandholt et al. (1992b, 1993b). Lockwood et al. (1993a) studied the latitudinal structure of one eastward-and one westward-moving event and showed in both cases the $557.7 \mathrm{~nm}$-dominant transient was a narrow $(\leq 10 \mathrm{~km})$ region on the edge of the much broader $\left({ }_{\sim}^{>} 200 \mathrm{~km}\right) 630 \mathrm{~nm}$-dominant transient. In both cases, this narrow green line arc was co-located with the upward field aligned current required to transfer the longitudinal motion to the ionosphere. The plasma velocity was large in the region of $630 \mathrm{~nm}$ emission and equal to the event motion. Hence these authors consider the $630 \mathrm{~nm}$-dominant transient to be the region of newly-opened flux and the $557.7 \mathrm{~nm}$ transient to be the region of upward field aligned current. For westward-moving events, this is on the poleward edge of the event and strong in intensity, but for eastward-moving events it is on the equatorward edge and weak. This therefore differs from the concept used by Fasel et al. (1992) and Sandholt and Newell (1992) who attribute the $557.7 \mathrm{~nm}$ emissions to particles ejected from the reconnection X-line: Fasel et al., consequently equate multiple brightening of $557.7 \mathrm{~nm}$ transients with multi-X line reconnection whereas Lockwood et al. (1933a) attribute them to variations in the stability of the upward field aligned current. Sandholt (1991) reported some weak sunward-moving events poleward of the cusp when IMF $B_{z}>0$ these may have resulted from transient lobe reconnection.

The observations of Lockwood et al. (1993a) are in very good agreement with the model of FTE signatures put forward by Cowley et al., (1991a), based on the Cowley-Lockwood (1992) flow excitation model (discussed in Section 5) and the complimentary ideas by Pudovkin (1991) and Pudovkin et al. (1992). This model is in principle the same as that put forward by Southwood $(1985 ; 1987)$, but the shape of the region of newly-opened flux is not considered fixed and circular (as used, for example, by Bosqued et al. 1991) but evolves with the ionospheric flow which returns the system toward equilibrium with the increased open magnetic flux. Hence the Cowley et al., (1991a) model is significantly different from the rigid 'moving-cloud' (circular or elliptical) models which evolved from Southwood's 
(1985, 1987) illustration (eg. McHenry and Clauer, 1988; Wei and Lee, 1990; Lockwood et al. 1990; Chatson et al., 1993) although, as noted by Lockwood et al. (1993d), an elliptical moving cloud model is approximately correct early in the lifetime of events when moving east/west under magnetic tension for strong $I M F\left|B_{y}\right|$. Careful reading of the text of the Southwood papers (rather than concentrating on his illustrative figure) shows that the Cowley et al. model is consistent with Southwood's original considerations.

Another key prediction of the Cowley et al. model is the existence of jumps in the cusp ion spectrograms (Smith et al., 1992). Independent of these theoretical predictions, examples of such jumps were published by Newell and Meng (1991). Lockwood and Smith (1992; 1994) showed that these examples were produced by reconnection which was, at that MLT, entirely pulsed in time or which showed a pulsed variation with MLT. The temporal explanation also predicts the jumps should occur between poleward-drifting events and this was confirmed by joint DMSP-EISCAT observations by Lockwood et al. (1993b). These data also showed the reconnection was near the subsolar point as was also deduced by Phillips et al. (1993) from mid-altitude cusp observations. The Cowley et al. (1991a) model was also used by Escoubet et al. (1992) to explain a 'staircase' cusp ion spectrogram with several cusp ion jumps and by Lockwood et al. (1993c) to explain high resolution (10-s) flow measurements by the two EISCAT radars and the behaviour of the simultaneously observed $630 \mathrm{~nm}$ aurora.

The observations of cusp ion jumps produced by dayside reconnection in short $(\sim 1 \mathrm{~min})$ pulses, with longer $(5-10 \mathrm{~min})$ intervals of no detectable reconnection, are direct evidence in favour of the 'pulsating cusp' model put forward by Lockwood and Smith (1989) and Smith and Lockwood (1990). That a series of transient events, each lasting a period greater than the repeat interval between them, can reproduce a 'persistent' cusp and the cusp precipitation statistics was demonstrated by Smith et al. (1992) and is directly shown by the EISCAT DMSP data presented by Lockwood et al. (1993b) (see Lockwood and Smith, 1994). Another combined radar-satellite observation of the pulsating cusp was presented by Pinnock et al. (1993). These authors showed that the cusp precipitation was present on an eastward flow channel (consistent with the cusp being on newly-opened field lines) as observed by the DMSP F9 satellite. This flow channel was also detected by the Halley Bay PACE radar, but was observed to be a transient feature, like these observed by the EISCAT radar during dayside breakup events (Lockwood et al. 1988, 1989, 1990). Pinnock et al. also highlight the non-uniform nature of the flow in the event, consistent with the Cowley et al. (1991a) FTE signature model, but not predicted by the circular or elliptical 'moving-cloud' models (Smith et al., 1992).

Pinnock et al. (1991) pointed out the value of conjugate observations in distinguishing transient reconnection and pressure pulse phenomena. However, the longitudinal coverage needs to be large in one or both hemispheres because of the opposite $\mathrm{B}_{\mathrm{y}}$-dependent shifts of the conjugate points, as predicted by Cowley et al. (1991b).

For this review of large-scale fields and flows, the important question is "how much do these transient events contribute to day-to-night flux transport"? Denig et al. (1993) find the flow voltage across three (small) dayside auroral transients is a very small fraction of the total transpolar voltage. However, this voltage is that associated with the east-west flow and is

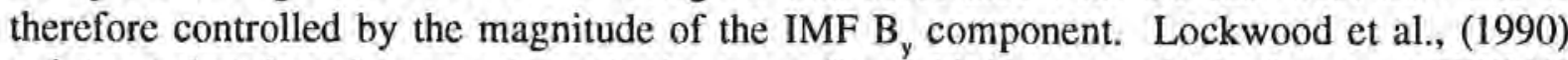
point out that the relevant voltage is the mean flux addition rate which, from the EISCAT 
flow channels, observed in association with dayside transient events, can be up to about half of a typical transpolar voltage. The magnetic flux associated with magnetopause FTE events is not known because their extents in only 2 of 3 dimensions have been measured: two-satellite observations yield a boundary normal extent of $\sim 1 R_{E}$, and the duration of events yields an extent of also $\sim 1 \mathrm{R}_{\mathrm{E}}$ for the dimension in the magnetopause, along their direction of motion. However, the extent in the third dimension, normal to their direction of motion, is unknown. Ionospheric observations are of vital importance here, as the ionospheric magnetic field is roughly constant and hence one just needs to measure the area of events and their repetition rate to evaluate the mean flux addition rate.

Sandholt et al., (1992b) studied some relatively small 630nm dayside breakup events and derived a contribution to convection of $20 \mathrm{kV}$. However, it should be noted these events were clearly defined in the field-of-view of one all-sky camera. Pudovkin et al. (1992) and Leontyev et al. (1992) report that events frequently extend beyond the contiguous field of view of a longitudinal chain of 3 or 4 all-sky cameras, making them in excess of $1000 \mathrm{~km}$ long. Furthermore, Lockwood et al. (1993a) point out that the 630nm emission probably arises from an altitude much greater than the $250 \mathrm{~km}$ employed by Sandholt et al and hence it is possible that events could sometimes be the only reconnection contribution to convection (as also found from the cusp jumps). Longitudinal extents of $1000-2000 \mathrm{~km}$ were also deduced from radar flow data by Lockwood et al. (1990) and Pinnock et al. (1993).

Lastly, Leontyev et al. (1992) report that most transient dayside aurorae drift poleward, but that a number do drift equatorward. Initially this appears to indicate $\mathrm{NB}_{z}$ transients (as discussed by Sandholt (1991), TCV-associated events (see next session) or even the hypothesised 'Plasma Transfer Events' (impulsive penetration events - see Section 4-i). However, Leontyev et al., use the longitudinal camera chain to show that equatorward motions tend to be away from noon and associated with a poleward-moving transient event nearer noon. Hence this also is in excellent agreement with the Cowley et al. (1991a) model as both poleward motion near noon and equatorward motion away from noon result from the return of the system towards equilibrium (see also Lockwood et al., 1993c).

Lui and Sibeck (1991) suggest that poleward-moving dayside auroral transients are caused by pressure pulses in the magnetosheath and that the associated flow bursts arise from ionospheric conductivity changes. One important confusion found in this paper concerns the relationship of dayside breakup transients to UV bright spots seen by the Viking imager. The extensive ( $200 \mathrm{~km}$ wide) red dominant transient caused by magnetosheath-like precipitation (the cusp) would lie poleward of the main UV auroral oval, as clearly demonstrated for quasi-steady conditions by Viking-DMSP comparisons (Elphinstone et al. 1992), and would not give rise to strong UV emission. The thin $(<10 \mathrm{~km})$ and shorter-lived green line transients (in which conductivities are enhanced) would be difficult to detect in UV images.

\section{(9-iv) Travelling Convection Vortices}

This class of dayside event was first reported by Fris-Christiansen et al., (1988) and Glassmeier et al., (1989) using ground magnetometer data. These authors noted that these events were not consistent with flux transfer event signatures because the plasma flow at the event centre was different in speed and direction from the phase motion of the event as a whole. Early indications implicated solar wind dynamic pressure pulses as a cause. 
Sibeck (1993) has shown that events showing this class of magnetic field deflection are associated with optical transients moving equatorward from the cusp, as well as with magnetic signatures at low latitudes and at geosynchronous orbit. Comparison of data from GOES5 and GOES6 shows events move anti-sunward away from noon with no IMF $B_{y}$ effect. Erlandson et al. (1991) tracked similar disturbances back to the magnetopause and showed that they arose at approximately the same time that solar wind dynamic pressure pulses seen by IMP-8 were predicted to impact on the magnetosphere. Extensive multi-point observations of what are now termed TCVs was presented by Potemra et al. (1992) and Chmyrev et al. (1991).

A theory which allowed the generation of such convection twin vortices by either increases or decreases in solar wind dynamic pressure was devised by Kivelson and Southwood (1991) and Lysak and Lee (1992), who showed how spatial gradients in the LLBL can couple the compressional motions of the magnetopause into filamentary field-aligned currents. Without such an effect, the compressional wave would reflect from the incompressible ionosphere and there would be no significant ionospheric flow signature of solar wind dynamic pressure pulses. The filamentary field-aligned currents required to explain TCVs have been modelled by Glassmeier (1992) and Glassmeier and Heppner (1992) and found to be large, peaking at about $1 \mu \mathrm{m}^{-2}$. These authors point out that the polarity of the leading current (i.e. the rotational sense of the vortices) depends on whether the magnetosphere is rarefied or compressed, but either yields a full twin vortex. They also consider the effects of Alfven wave bouncing when the source is moving with the magnetosheath flow.

It is now clear that several early attempts to detect ionospheric FTE signatures found, in reality, TCV events. One undisputed example is that reported from EISCAT radar data by Todd et al. (1986), which Sibeck et al. (1989) found to be associated with a solar wind dynamic pressure pulse and Lühr et al. (1993) have shown was a TCV. Similarly, the magnetic impulse events reviewed by Lanzerotti et al. (1991) now appear to be mainly TCVs. Sibeck and Croley (1991) argue that the original pulative FTE described in STARE radar data by Goertz et al. (1985) is also a TCV. FTE signatures do not appear to be the simple, localised twin vortices that were originally envisaged from circular moving-cloud models (see previous section) and the last two years have done much to clear up the confusion which arose.

\section{Personal conclusions}

Given the large volume of significant work described in the previous sections, it would be unwise to attempt to conclude by summarising the findings of the review period, other than to note that great progress was made in a wide variety of areas and that as some questions were solved, so many new puzzles were revealed. Rather, I here offer some general thoughts which occurred to me as I read the literature. These thoughts concern some general trends and tendencies and are purely personal opinions.

The 'synthesis' of apparently conflicting models is of great potential value. I would cite two examples: the $\mathrm{CD}$ and NENL substorm models and the combination of high-latitude boundary layer voltage source with the LLBL current source are both examples where such synthesis looks set to provide great steps forward in our understanding in the near future. On the other hand attempting to find an all-embracing concept has its dangers. One of these is the tendency for different observing techniques to stress different phenomena. As an 
example of this, I would argue that dayside ground-based magnetometers are well-suited to observe the TCV phenomenon, seemingly produced by solar wind dynamic pressure pulses, whereas the most dramatic events seen in ground based radar and optical observations are the dayside breakup events, apparently best described by the latest models of the effects of transient magnetopause reconnection. Hence attempts to combine all dayside transients into signatures of one or other type of event are not constructive. It may well be that these two phenomena are not entirely independent (e.g. reconnection bursts may be caused by pulses of increased solar wind pressure) but it is now clear that to fail to recognise the differences between these two class of events causes problems.

Furthermore, we must acknowledge that the magnetosphere is complex and variable. For example I would argue that, despite a common set of repeatable signatures in substorms, it is not necessarily true that all substorms will be adequately described by any one paradigm. As pointed out by Chris Russell (private communication, 1993), we still have no recognised and adequate way of quantifying the strength of a substorm and our definition of an "isolated" substorm is subjective. That the occurrence statistics of events like substorms and FTEs appear to depend critically on the criteria we use to define them indicates that there may be broader continua of behaviour than we care to consider.

It occurs to me that the quality of scientific debate all too often is lowered by the technique of "setting up a strawman and then knocking him down". Much time and too many journal pages are wasted by unilaterally attributing an event to a certain class of phenomenon and then raising difficulties for a rival theory, when those difficulties all depend on the original classification. For this reason, different viewpoints on the same events (e.g. CDAW intervals) have been much more enlightening. A related problem arises over the names we employ for events and phenomena: often these names betray (rightly or wrongly) a bias towards a given theory (to my mind "flux transfer events" and "cusp precipitation" are two such culprits). Names that are not loaded with meaning (like Region 1 and 2 field-aligned currents) may be more bland and cumbersome but can never mislead us.

In reviewing the literature, one cannot help but be struck by the shift in perceptions brought about by the improvements in accuracy, resolution and coverage of the ionospheric flow snapshots now available to us. As these continue, so new layers of temporal and spatial structure are bound to be revealed. The shift away from time-averaged concepts make induction effects important and hence it is vital to measure ionospheric and magnetospheric flows separately and not map fields nor flows using steady state concepts which apply only to longer time scales.

\section{Acknowledgements}

My thanks go to Janet Foster of the Rutherford Appleton Laboratory for photocopying and typing the references. The full list of references is available electronically, on request to MIKE@EISCAT.AG.RL.AC.UK. 


\section{REFERENCES}

Ahn, B.-H., Y. Kamide, H.W. Kroehl, and D.J. Gorney, Cross-polar potential difference, auroral electrojet indices, and solar wind parameters, J. Geophys. Res., 97, 1345-1352, 1992.

Aikio, A.T., H.J. Opgenoorth, M.A.L. Persson, and K.U. Kaila, Ground-based measurements of an arc-associated electric field, J. Atmos. Terr. Phys. 55, 797-808, 1993.

Akasofu, S.-I., C.-I. Meng, and K. Makita, Changes of the size of the open field line region during substorms, Planet. Space Sci., 40, 1513-1524, 1992.

Anderson, P.C., W.B. Hanson, R.A. Heelis, J.D. Craven, D.N. Baker, and L.A. Frank, A proposed production model of rapid subauroral ion drifts and their relationship to substorm evolution, J. Geophys. Res., 98, 6069-6078, 1993.

Anderson, P.C., R.A. Heelis and W.B. Hanson, The ionospheric signatures of rapid subauroral ion drifts, J. Geophys. Res., 96, 5785-5792, 1991.

Angelopoulos, V., W. Baumjohann, C.F. Kennel, F.V. Coroniti, M.G. Kivelson, R.Pellat, R.J. Walker, H. Lühr and G. Paschmann, Bursty bulk flows in the inner central plasma sheet, I. Geophys. Res., 97, 4027-4039, 1992a.

Angelopoulos, V., C.F. Kennel, F.V. Coroniti, R. Pellat, M.G. Kivelson, R.J. Walker, W. Baumjohann, G. Paschmann, and H. Lühr, Bursty bulk flows in the inner central plasma sheet: an effective means of earthward transport in the magnetotail, in "Substorms $I$, Proceedings of the First International Conference on Substorms, ICS-I", ed C. Mattock, ESA$S P-335,303-308$, European Space Agency Publications, Nordvijk, The Netherlands, 1992b.

Antonova E.E., The development of initial substorm expansive phase disturbance due to generation of localized electric fields in the region of maximum upward field-aligned current, Adv. Space Res., 13, (4)261-(4)264, 1993.

Aparicio, B., B. Thelin, and R. Lundin, The polar cusp from a particle point of view: a statistical study based on Viking data, J. Geophys, Res., 96, 14,023-14,031, 1991.

Atkinson, G., How does magnetospheric convection relate to the expansion onset of substorms?, J. Atmos. Terr. Phys., 55, 1151-1157, 1993.

Baker, D. N., and R.L. McPherron, Extreme energetic particles decreases near geostationary orbit: a manifestation of current diversion within the inner plasma sheet, $J$. Geophys. Res., 95, 6591-6600, 1990.

Baker, D.N,, A.J. Klimas, T.I. Pulkkinen, and R.L. McPherron, Re-examination of driven and unloading aspects of magnetospheric substorms, Adv. Space Res., 13, (4)75-(4)83, 1993a.

Baker, D.N., A.J. KLimas, and D.A. Roberts, Examination of time-variable input effects in a nonlinear analogue magnetosphere model, Geophys. Res. Lett., 18, 1631-1634, 1991.

Baker D.N., T.I. Pulkkinen, R.L. McPherron, J.D. Craven, L.A. Frank., R.D. Elphinstone, J.S. Murphree, J.F. Fennel, R.E. Lopez, and T. Nagai, CDAW 9 analysis of magnetospheric events on May 3 1986: event C, J. Geophys. Res., 98, 3815-3834, 1993 b.

Baumjohann, W., G. Paschmann, and C.A. Cattell, Average plasma properties in the central plasma sheet, J. Geophys. Res., 94, 6597-6606, 1989.

Baumjohann, W., G. Paschmann, and T. Nagai, Thinning and expansion of the substorm plasma sheet, J. Geophys. Res., 97, 17,173-17,175, 1992.

Baumjohann, W., G. Paschmann, T. Nagai, and H. Lühr, Superposed epoch analysis of the substorm plasma sheet, I. Geophys. Res., 96, 11,605-11,608, 1991. 
Belenkaya, E., Comment on "Observations of reconnection of interplanetary and lobe magnetic field lines at the high-latitude magnetopause" by J.T. Gosling, M.F. Thomsen, S.J. Bame, R.C. Elphic, and C.T. Russell, J. Geophys. Res., 98, 5941-5944, 1993.

Belenkaya, E.S., I.I. Alexeev, and V.V. Kalegaev, Electromagnetic interactions of the solar wind generator with the magnetosphere carried by field-aligned currents, Adv. Space Res., 13, (4)33-(4)35, 1993.

Birn, J., Quasi-steady current sheet structures with field-aligned flow, J. Geophys. Res., 97, 16,817-16,826, 1992a.

Birn, J., On the termination of the closed field line region of the magnetotail, J, Geophys, Res., 97, 14,833-14,840, 1992b.

Birn J., and M. Hesse, MHD simulations of magnetic reconnection in a skewed threedimensional tail configuration, J. Geophys, Res., 96, 23-24, 1991a.

Birn, J., and M. Hesse, The substorm current wedge and field-aligned currents in MHD simulations of magnetotail reconnection, $J$. Geophys Res., 96, 1611-1618, 1991b.

Birn, J., M. Hesse, and K. Schindler, What determines the latitudinal extent of the auroral acceleration region?, J. Atmos. Terr. Phys., 55, 1171-1184, 1993.

Birn, J., E.W. Hones, Jr., J.D. Craven, L.A. Frank, R.D. Elphinstone, and D.P. Stern, On open and closed field line regions in Tsyganenko's field model and their possible associations with horse collar auroras, J. Geophys. Res., 96, 3811-3817, 1991.

Blanchard G.T., and R.L. McPherron, A bimodal representation of the response function relating the solar wind electric field to the AL index, Adv. Space Res., 13, (4)71-(4)74, 1993.

Blomberg, L.G., and G.T. Marklund, High-latitude convection patterns for various largescale field-aligned current configurations, Geophys. Res. Lett., 18, 717-720, 1991.

Bol'shakova, O.V., B.I. Klayn, and N.A. Kurazhovskaya, The relation between generation of high-latitude vlp pulsations and solar wind inhomogeneities, Geomag. and Aeron., 31, 795$800,1991$.

Borovsky, J.E., R.J. Nemzek, and R.D. Belian, The occurrence rate of magnetosphericsubstorm onsets: random and periodic substorms, J. Geophys. Res., 98, 3807-3813, 1993.

Bosqued J.M., A. Berthelier, J.J. Berthelier, and C.P. Escoubet, A case study of the cusp electrodynamics by the aureol-3 satellite: evidence for FTE signatures?, Geophys. Res. Lett., 18, 1833-1836, 1991.

Buonsanto, M.J., J.C. Foster, and D.P. Sipler, Observations from Millstone Hill during the geomagnetic disturbances of March and April 1990, J. Geophys. Res., 97, 1225-1243, 1992.

Buonsanto, M.J., M.E. Hagen, J.E. Salah, and B.G. Fejer, Solar cycle and seasonal variations in F region electrodynamics at Millstone Hill, J. Geophys. Res., 98, 15677-15684, 1993.

Burch, J.L., N.A. Saflekos, D.A. Gurnett, J.D. Craven, and L.A. Frank, The quiet time polar cap: DE 1 observations and conceptual model, J. Geophys. Res., 97, 19,403-19,412, 1992.

Burke W.J., B. Jacobsen, P.E. Sandholt, W.F. Denig, N.C. Maynard and P.T. Newell, Optical signatures and sources of prenoon auroral precipitation, $J$. Geophys. Res., 98, 11,251$11,529,1993$.

Burkhart, G.R., J.F. Drake, and J. Chen, Structure of the dissipation region during magnetic reconnection in collisionless plasma, J. Geophys, Res., 96, 11,539-11,553, 1991.

Burkhart G.R., J.F. Drake, P.B. Dusenbery, and T.W. Speiser, Ion tearing in a magnetotail configuration with an embedded thin current sheet, J. Geophys. Res., 97, 16,749-16,756, 1992. 
Cahill, L.J. Jr., and J.R. Winckler, Periodic magnetopause oscillations observed with the GOES satellites on March 24 1991, J. Geophys. Res., 97, 8239-8243, 1992.

Cannon, P.S., G. Crowley, B.W. Reinisch, and J. Buchau, Digisonde measurements of polar cap convection for northward interplanetary magnetic field, J. Geophys. Res., 97, $16,877-16,885,1992$.

Cannon, P.S., B.W. Reinisch, J. Buchau, and T.W. Bullett, Response of the polar cap F region convection direction to changes in the interplanetary magnetic field: digisonde measurements in northern Greenland, J. Geophys. Res., 96, 1239-1250, 1991.

$\mathrm{CaO}, \mathrm{F}$., and J.R. Kan, Oblique tearing of a thin current sheet: implications for patchy magnetopause reconnection, J. Geophys. Res., 96, 5859-5867, 1991.

Carr, S.S., T.L. Killeen, and W.R. Coley, Remote-sensing observations of F-region ion drifts velocities using Dynamics Explorer-2 doppler measurements of the $\mathrm{O}+\left({ }^{2} \mathrm{P}\right) \lambda 732.0 \mathrm{~nm}$ emission, Geophys. Res. Lett., 19, 1455-1458, 1992.

Chatson, C.C., H.J. Hansen, F.W. Menk, B.J. Fraser, and Y.D. Hu, Ground signatures of convecting reconnected flux tubes, J. Geophys. Res. 98, 19151-19162, 1993.

Chmyrev, V.M. V.A. Marchenko, O.A. Pokhotelov, L. Stenflo, A.V. Streltsov and Ä.Steen, Vortex structures in the ionosphere and the magnetosphere of the earth, Planet. Space Sci., 39, 1025-1030, 1991.

Chun, F.K. and C.T. Russell, The evolution of field-aligned currents as a function of substorm phase, J. Geophys. Res., 96, 15,801-15,810, 1991.

Cowley, S. W. H., The causes of convection in the Earth's magnetosphere: A review of developments during IMS, Rev. Geophys., 20, 531-565, 1982.

Cowley, S.W.H., Acceleration and heating of space plasmas: basic concepts, Ann. Geophys., 9, 176-187, 1991a.

Cowley, S.W.H., The role and location of magnetic reconnection in the geomagnetic tail during substorms, in "Substorms 1, Proceedings of the First International Conference on Substorms, ICS-I", ed C. Mattock, ESA-SP-335, 401-404, European Space Agency Publications, Nordvijk, The Netherlands, 1992.

Cowley, S.W.H,, and M. Lockwood, Excitation and decay of solar wind-driven flows in the magnetosphere-ionosphere system, Ann. Geophys., 10, 103-115, 1992.

Cowley, S.W.H., M.P. Freeman, M. Lockwood, and M.F. Smith, The ionosphere signature of flux transfer events, in "CLUSTER - dayside polar cusp", ed. C.I Barron, ESA SP-330, 105-112, European Space Agency Publications, Nordvijk, The Netherlands, 1991a.

Cowley, S.W.H., J.P. Morelli, M.P. Freeman, M. Lockwood and M.F. Smith,

Excitation and decay of flows in the magnetosphere-ionosphere system due to magnetic reconnection at the dayside magnetopause and in the geomagnetic tail, in "Substorms 1, Proceedings of the First International Conference on Substorms, ICS-I", ed C. Mattock, ESA$S P-335,117-124$, European Space Agency Publications, Nordvijk, The Netherlands, 1992.

Cowley, S.W.H., J.P. Morelli and M. Lockwood, Dependence of convective flows and particle precipitation in the high-latitude dayside ionosphere on the $\mathrm{X}$ and $\mathrm{Y}$ components of the interplanetary magnetic field, J. Geophys. Res., 96, 5557-5564, 1991 b.

Crooker N.U., Reverse convection, J. Geophys. Res., 97, 19,363-19,372, 1992.

Crooker, N.U., and F.J. Rich, Lobe-cell convection as a summer phenomenon, J. Geophys. Res., 98, 13,403-13,407, 1993.

Crooker N.U., G.L. Siscoe, and F.R.Toffoletto, Reply, J. Geophys. Res., 96, 1875, 1991a.

Crooker N.U., F.R. Toffoletto, and M.S. Gussenhoven, Opening the cusp, J. Geophys. Res., 96, 3497-3503, $1991 \mathrm{~b}$. 
Crowley, G., P.S. Cannon, C.G. Dozois, B.W. Reinisch and J. Buchau, Polar cap convection for $\mathrm{B}_{\mathrm{z}}$ northward, Geophys. Res, Lett.s 19, 657-660, 1992.

Cumnock, J.A., R.A. Heelis and M.R. Hairston, Response of the ionospheric convection pattern to a rotation of the interplanetary magnetic field on January 14 1988, J. Geophys. Res., 97, 19,449-19,460, 1992.

Daglis I.A., E.T. Sarris, and G. Kremser, Ionospheric contribution to the cross-tail current enhancement during the substorm growth phase, J. Atmos. Terr. Phys., 53, 1091-1098, 1991.

de la Beaujardiere, O., D. Alcayde, J. Fontanari, and C. Leger., Seasonal dependence of high-latitude electric fields, J. Geophys, Res., 96, 5723-5735, 1991a.

de la Beaujardiere, O., L.R. Lyons, and E. Friis-Christensen, Sondrestrom radar measurements of the reconnection electric field, J. Geophys. Res., 96, 13,907-13,912, 1991b.

de al Beaujardiere O., P. Newell, and R. Rich, Relationship between Birkeland current regions, particle participation, and electric fields, J. Geophys. Res., 98, 7711-7720, 1993.

Denig, W.F., W.J. Burke, N.C. Maynard, F.J. Rich, B. Jacobsen, P.E. Sandholt, A. Egeland, S.Leontjev, and V.G. Vorobjev, Ionospheric signatures of dayside magnetopause transients: a case study using satellite and ground measurements, J. Geophys. Res., 98, 5969$5980,1993$.

Denisenko V.V., and S.S. Zamay, Mathematical modelling of global electric fields and currents in the ionosphere, Geomag. \& Aeron., 31, 428-431, 1992.

Denisenko V.V., S.S. Zamay, A.V. Kitayez, I.T. Matveyenkov, and V.G. Pivovarov, System of ionospheric currents, excited by magnetospheric generator in surface layer, Geomag. \& Aeron., 32, 428-430, 1992.

Diebold, D.A., N. Hershkowitz, J.R. DeKock, T.P. Intrator, S.-G. Lee, and M-K. Hsieh, Space charge enhanced, plasma gradient induced error in satellite electric field measurements, J. Geophys. Res., 98, 449-458, 1993.

Ding, D.G., and L.C. Lee, Particle simulations of collisionless magnetic reconnection in magnetospheric current sheets, Adv. Space Res., 11, (9)117-(9)127, 1991.

Ding, D.G., L.C. Lee, and C.F. Kennel, The beta dependence of the collisionless tearing instability at the dayside magnetopause, J. Geophys. Res., 97, 8257-8267. 1992a.

Ding, F.G., L.C. Lee, and Z.W. Ma, Different FTE signatures generated by the bursty single $\mathrm{X}$ line reconnection and the multiple $\mathrm{X}$ line reconnection at the dayside magnetopause, J. Geophys. Res., 96, 57-66. 1991.

Ding, D.Q., L.C. Lee, and D.W. Swift, Particle simulations of driven collisionless magnetic reconnection at the dayside magnetopause, J. Geophys. Res., 97, 8453-8481, $1992 \mathrm{~b}$.

Donovan, E.F., and G. Rostoker, Internal consistency of the Tsyganenko magnetic field model and the Heppner-Maynard empirical model of the ionospheric electric field distribution, Geophys. Res. Lett., 18, 1043-1046, 1991.

Dudeney, J.R., A.S. Rodger, M. Pinnock, J.M. Ruohoniemi, K.B. Baker, and R.A. Greenwald, Studies of conjugate plasma convection in the vicinity of the Harang discontinuity, J. Atmos Terr. Phys., 53, 249-263, 1991.

Elphic, R.C., Multipoint observations of the magnetopause: Results from ISEE and AMPTE, Adv. Space Res., 8(9), 223-238, 1988.

Elphinstone, R.D., and D.J. Hearn, The auroral distribution and its relation to magnetospheric processes, Adv. Space Res., 13, (4)17-(4)27, 1993.

Elphinstone, R.D., D.J. Hearn, J.S. Murphree, and L.L. Cogger, Mapping using the Tsyganenko long magnetospheric model and its relationship to Viking auroral images, $J$. Geophys. Res., 96, 1467-1480, 1991. 
Elphinstone, R.D., K. Jankowska, J.S. Murphree, and L.L. Cogger, The configuration of the northern auroral distribution for interplanetary magnetic field $B_{z}$ northward, 1. IMF $B_{z}$ and $\mathrm{B}_{\mathrm{y}}$ dependencies as observed by the Viking satellite, J. Geophys. Res., 95, 7591, 1990.

Elphinstone, R.D., J.S. Murphree, D.J. Hearn, L.L. Cogger, P.T. Newell, and H. Vo, Viking observations of the UV dayside aurora and their relationship to DMSP particle boundary definitions, Ann. Geophys., 10, 815-826, 1992.

Erickson, G.M. and R.A. Wolf, Is steady-state convection possible in the Earth's magnetotail?, Geophys. Res. Lett., 7, 897-900, 1980.

Erlandson, R.E., D.G. Sibeck, R.E. Lopez, L.J. Zanetti, and T.A. Potemra, Observations of solar wind pressure initiated fast mode waves at geostationary orbit and in the polar cap. J. Atmos. Terr. Phys., 53, 231-240, 1991.

Escoubet, C.P., M.F. Smith, S.F. Fung, P.C. Anderson, R.A. Hoffman, E.M. Basinska and J.M. Bosqued, Staircase ion signature in the polar cusp: a case study, Geophys. Res. Lett., 19. 1735-1738, 1992

Etemadi, A., S. W. H. Cowley, M. Lockwood, B. J. I. Bromage, D. M. Willis, and H. Luehr, The dependence of high-latitude dayside ionospheric flows on the north-south component of the IMF, a high time resolution correlation analysis using EISCAT "POLAR" and AMPTE UKS and IRM data, Planet. Space Sci., 36, 471, 1988.

Fairfield, D.H., Advances in magnetospheric storm ad substorm research: 1989-1991, J. Geophys. Res., 97, 10,865-10,874, 1992.

Farrugia, C.J., M.P. Freeman, L.F. Burlaga, R.P. Lepping and K. Takahashi, The Earth's magnetosphere under continued forcing: substorm activity during the passage of an interplanetary magnetic cloud, J. Geophys. Res., 98, 7657-7671, 1993.

Farrugia, C. J., R. P. Rijnbeek, M. A. Saunders, D. J. Southwood, D. J. Rodgers, M. F. Smith, C. P. Chaloner, D. S. Hall, P. J. Christiansen, and L. J. C. Woolliscroft, A multi-instrument study of flux transfer event structure, J. Geophys. Res., 93, 14465-14477, 1988.

Fasel, G.J., J.I. Minow, R.W. Smith, C.S. Deehr, and L.C. Lee, Multiple brightenings of transient dayside auroral forms during oval expansions, Geophys. Res. Lett., 19, 2429-2432, 1992 .

Fedder, J.A., C.M. Mobarry, and J.G. Lyon, Reconnection voltage as a function of IMF clock angle, Geophys. Res. Lett., 18, 1047-1050, 1991.

Feldstein, Y.I., and R.D. Elphinstone, Aurorae and the large-scale structure of the magnetosphere, J. Geomag. Geoelectr., 44, 1159-1174, 1992.

Feldstein, Ya.I., and Yu I. Galperin, An alternative interpretation of auroral precipitation and luminosity observations from the DE, DMSP, AUREOL, and Viking satellites in terms of their mapping to the nightside magnetosphere, J. Atmos. Terr. Phys. 55, 105-121, 1993.

Finch, J.M., and M.J. Rycroft, Field-aligned currents at the dayside magnetopause, reconnection and magnetic helicity, Adv. Space Res., 13, (4)45-(4)50, 1993.

Förster, M., V.M. Mishin, T.I. Saifudunova, A.D. Bazarshapov, D.S. Shirapov, and S.B. Lunyushkin, Contribution of two processes to magnetospheric energy and momentum input during the CDAW-W period, Ann. Geophys., 9, 495-499, 1991.

Foster, J.C., Storm time plasma transport at middle and high latitudes, J. Geophys. Res., 98. 1675-1689, 1993.

Fox, N.J., M. Lockwood, S.W.H. Cowley, M.P. Freeman, E. Friis-Christensen, D.K. Milling, M. Pinnock and G.D. Reeves, EISCAT observations of unusual flows in the morning sector associated with weak substorm activity, Annales Geophys. 12, 541-553, 1994. 
Freeman, M.P., C.J. Farrugia, L.F. Burlaga, M.R. Hairston, M.E. Greenspan, J.M. Ruohoniemi, and R.P. Lepping, The interaction of a magnetic cloud with the earth: ionospheric convection in the northern and southern hemispheres for a wide range of quasisteady interplanetary magnetic field conditions, J. Geophys. Res., 98, 7633-7655, 1993.

Freeman, M.P., J.M. Ruohoniemi, and R.A. Greenwald, The determination of timestationary two-dimensional convection patterns with single-station radar, J. Geophys. Res., 96, 15,735-15,749, 1991.

Freeman, M.P. and D.J. Southwood, The effects of magnetospheric erosion on mid- and high-latitude ionospheric flows, Planet. Space Sci., 36, 509, 1988.

Freeman, M.P., D.J. Southwood, M. Lester, T.K. Yeoman, and G.D. Reeves, Substormassociated radar auroral surges, J. Geophys.Res., 97, 12,173-12,185, 1992.

Friis-Christensen, E., M.A. McHenry, C.R. Clauer, and S. Vennerstrom, Ionospheric traveling convection vortices observed near the polar cleft: A triggered response to sudden changes in the solar wind, Geophys. Res. Lett., 15, 253-256, 1988.

Fuselier, S.A., D.M. Klumpar, and E.G. Shelley, Ion reflection and transmission during reconnection at the earth's subsolar magnetopause, Geophys. Res, Lett., 18, 139-142, 1991.

Fuselier, S.A., E.G. Shelley, and D.M. Klumpar, Mass density and pressure changes across the dayside magnetopause, J. Geophys. Res., 98, 3935-3942, 1993.

Galperin Y.I., and Y.I. Feldstein, Auroral luminosity and its relationship to magnetospheric plasma domains, in "Auroral Physics", 207-222, 1991.

Ganguli, S.B., H.G. Mitchell, and P.J. Palmadesso, Plasma dynamics driven by finite-width current filaments and $\mathrm{kV}$ potential drops in ionosphere-magnetosphere coupling, Geophys. Res. Lett., 20, 975-978, 1993.

Glaßmeier, K.-H., M. Hoenisch and J. Untied, Ground-based and satellite observations of traveling magnetospheric convection twin vortices, J. Geophys. Res., 94, 2520-2528, 1989.

Glaßmeier, K-H., Traveling magnetospheric convection twin-vortices: observations and theory, Ann. Geophys., 10, 547-565, 1992.

Glaßmeier, K-H., and C. Heppner, Traveling magnetospheric convection twin vortices: another case study, global characteristics, and a model, J. Geophys. Res., 97, 3977-3992, 1992.

Goertz, C.K., E. Neilsen, A. Korth, K.-H. Glassmeier, C. Haldoupis, P. Hoeg and D. Hayward, Observations of a possible signature of flux transfer events, J. Geophys. Res., 90. 4069-4078, 1985.

Goertz C.K., L-H Shan, and R.A. Smith, Prediction of geomagnetic activity, I. Geophys. Res., 98, 7673-7684, 1993.

Gosling J.T., M.F. Thomsen, S.J. Bame, R.C. Elphic, and C.T, Russell, Observations of reconnection of interplanetary and lobe magnetic field lines at the high-latitude magnetopause, J. Geophys. Res., 96, 14,097-14,106, 1991.

Gosling, J.T., M.F. Thomsen, S.J. Bame, R.C. Elphic, and C.T. Russell, Reply, J. Geophys. Res., 98, 5945,1993.

Gosling, J.T., M.F. Thomsen, S.J. Bame, R.C. Elphic, and C.T. Russell, Cold ion beams in the low latitude boundary layer during accelrated flow events, Geophys. Res. Lett., 17 , 2245-2248, 1990a.

Gosling, J.T., M.F. Thomsen, S.J. Bame, R.C. Elphic, and C.T, Russell, Plasma flow reversals at the dayside magnetopause and the origin of asymmetric polar cap convection, $J$. Geophys. Res., 95, 8073-8084, 1990 b.

Gonzalez, W.D., Comment on "A tangent subsolar merging line" by N.U. Crooker et al., 
J. Geophys, Res., 96, 1873-1874, 1991.

Greenwald, R.A., K.B. Baker, J.M. Ruohoniemi, J.R. Dudeney and M. Pinnock, Cusp studies with HF radars, in "CLUSTER - dayside polar cusp", ed. C.I Barron, ESA SP-330, 67-76, European Space Agency Publications, Nordvijk, The Netherlands, 1991

Greenwald, R.A., K.B. Baker, J.M. Ruohoniemi, J.R. Dudeney, N. Pinnock, N. Mattin, J.M. Leonard, and R.P. Lepping, Simultaneous conjugate observations of dynamic variations in high-latitude dayside convection due to changes in IMF $\mathrm{B}_{\mathrm{y}}, J$. Geophys. Res., 95, 8057$8072,1990$.

Haerendel, G., G. Paschmann, N. Sckopke, H. Rosenbauer, and P. C. Hedgecock, The frontside boundary layer of the magnetopause and the problem of reconnection, J. Geophys. Res., 83, 3195-3216, 1978.

Hanuise, C., C. Senior, J-C.Cerisier, J.-P. Villain, R.A.Greenwald, J.M. Ruohoniemi, and K.B. Baker, Instantaneous mapping of high-latitude convection with coherent HF radars, $J$. Geophys. Res., 98, 17387-17400, 1993.

Hapgood, M.A., and D.A. Bryant, Exploring the magnetospheric boundary layer, Planet. Space Sci, 40, 1431-1459, 1992.

Hapgood, M.A., and M. Lockwood, On the voltage and distance across the low latitude boundary layer, Geophys. Res. Lett., 20, 145-148, 1993.

Hapgood, M. A., Y, Tulunay, M. Lockwood, G. Bowe, and D. M. Willis, Variability of the interplanetary medium at 1 AU over 24 years: 1963-1986, Planet. Space Sci., 39, 411-423, 1991.

Heelis R.A., and W.R. Coley, East-west ion drifts at mid-latitudes observed by Dynamics Explorer 2, J. Geophys. Res., 97, 19,461-19,469, 1992.

Heikkila, W.J., Impulsive transport through the magnetopause, Geophys. Res. Lett., 9, 159$163,1982$.

Heikkila, W.J., Comment on Owen and Cowley's analysis of impulsive plasma transport through the magnetopause, J. Geophys. Res., 97, 1639, 1992.

Hesse, M., and J. Birn, On dipolarization and its relation to the substorm current wedge, J. Geophys. Res., 96, 19,417-19,426, 1991a.

Hesse, M., and J. Birn, Plasmoid evolution in an extended magnetotail, J. Geophys. Res., 96, 5683-5696, $1991 \mathrm{~b}$.

Hesse, M., and J. Birn, Magnetosphere-ionosphere coupling during plasmoid evolution: first results, J. Geophys. Res., 96, 11,513-11,522, $1991 \mathrm{c}$.

Hesse, M., and J. Birn, MHD modeling of magnetotail instability for anisotropic pressure, J. Geophys. Res., 97, 10,643-10,654, 1992a.

Hesse, M., and J. Birn, Three-dimensional MHD modeling of magnetotail dynamics for different polytropic indices, J. Geophys, Res., 97, 3965-3976, 1992 b.

Hesse, M., and D. Winske, Hybrid simulations of collisionless ion tearing, Geophys. Res. Lett., 20, 1207-1210, 1993.

Hill, T.W. and P.H. Reiff, Evidence of magnetospheric cusp proton acceleration by magnetic merging at the dayside magnetopause, J. Geophys. Res., 82, 3623-3628, 1977.

Hoshino, M., Forced magnetic reconnection in a plasma sheet with localized resistivity profile excited by lower hybrid drift type instability, J. Geophys. Res., 96, 11,555-11,567, 1991.

Huang, Y.-N., and K. Cheng, Ionospheric disturbances around East Asian region during the 20 October 1989 magnetic storm, J. Atmos Terr. Phys., 55, 1009-1020, 1993.

Huang, C.Y., L.A. Frank, G.Rostoker, J. Fennell, and D.G. Mitchell, Nonadiabatic heating 
of the central plasma sheet at substorm onset, J. Geophys. Res., 97, 1481-1495, 1992.

Israelevich, P.I., and N.S. Nikolaeva, High latitude ionospheric convection inferred from the distribution of field-aligned currents, Planet. Space Sci., 39, 1107-1117, 1991.

Ivanov, V.N., O.A. Pokhotelov, F.Z. Feygin, A. Ru, S. Perro, and D. Leko, The balloon instability in the terrestrial magnetosphere with irregular pressure and a finite $\beta$.

Geomag. and Aeron., 32, 211-216, 1992.

Jacobsen, B., P.E. Sandholt, B.Lybekk, and A. Egeland, Transient auroral events near midday: relationship with solr wind/magnetosheath plasma and magnetic field conditions, $J$. Geophys. Res., 96, 1327-1336, 1991.

Jacquey, C., J.A. Sauvaud, J. Dandorous, and A Korth, Tailward propagation cross-tail current disruption and dynamics of near-earth tail: a multi-point measurement analysis, Geophys, Res. Lett., 20, 983-986, 1993.

Kamide Y., Is substorm occurrence a necessary condition for a magnetic storm?, $J$. Geomag. Geoelectr., 44, 109-117, 1992.

Kamide Y., and A.D. Richmond, Ground-based studies of sensing magnetosphere/ionosphere interactions: convection and substorms, in "CLUSTER - dayside polar cusp", ed. C.I Barron, ESA SP-330, 129-138. European Space Agency Publications, Nordvijk, The Netherlands, 1991.

Kan, J.R., Dipolarization: a consequence of substorm expansion onset, Geophys. Res. Lett., 18, 57-60, 1991.

Kan, J.R., On the cause of substorm expansion onset and the processes driving the substorm expansion phase, J. Atmos Terr. Phys., 55, 979-983, 1993 a.

Kan, J.R., A global magnetosphere-ionosphere coupling model of substorms, J. Geophys. Res., 98, 17263-17276, 1993 b.

Kawano, H., S. Kokubun, and K. Takahashi, Survey of transient magnetic field events in the dayside magnetosphere, J, Geophys. Res., 97, 10,677-10,692, 1992.

Kelley, M.C., D.J. Knudsen, and J.F. Vickrey, Poynting flux measurements on a satellite: a diagnostic tool for space research, J. Geophys. Res., 96, 201-207, 1991.

Kennel, C.F., The Kiruna conjecture: the strong version, in "Substorms I, Proceedings of the First International Conference on Substorms, ICS-I", ed C. Mattock, ESA-SP-335, 599602, European Space Agency Publications, Nordvijk, The Netherlands, 1992.

Kettmann, G., T.A. Fritz, and E.W. Hones Jr, CDAW-7 revisited: Further evidence for the creation of a near-earth substorm neutral line, J. Geophys. Res., 95, 12,045, 1990.

Kettman, G,, T.A, Fritz, E.W. Hones Jr, and P.W. Daly, Energetic ion anisotropies in the geomagnetic tail 2. Magnetic field and substorm characteristics, J. Geophys. Res., 98, 115129, 1993.

Kidd, S.R., and G. Rostoker, Distribution of auroral surges in the evening sector, $J$. Geophys. Res., 96, 5697-5706, 1991.

Kirkwood, S., An improved conductivity model for substorm modelling, in "Substorms 1, Proceedings of the First International Conference on Substorms, ICS- $1^{\prime \prime}$, ed C. Mattock, ESASP-335, 599-602, European Space Agency Publications, Nordvijk, The Netherlands, 1992.

Kistler, L.M., E. Möbius, W. Baumjohann, G. Paschmann, and D.C. Hamilton, Pressure changes in the plasma sheet during substorm injections, J. Geophys, Res., 97, 2973-2983, 1992.

Kistler, L.M., W. Baumjohann, T. Nagai, and E. Möbius, Superposed epoch analysis of pressure and magnetic field configuration changes in the plasma sheet, J. Geophys. Res,, 98, 9249-9258, 1993. 
Kivelson, M.G., and D.J. Southwood, Ionospheric travelling vortex generation by solar wind buffeting of the magnetosphere, J. Geophys. Res., 96, 1661-1667, 1991.

Klimas, A.J., D.N. Baker, and D.A. Roberts, Linear prediction filters for linear and nonlinear modeled geomagnetic activity, Geophys. Res. Lett., 18, 1635-1638, 1991.

Knipp, D.J., B.A. Emery, A.D. Richmond, N.U. Crooker, M.R. Hairston, J.A. Cumnock, W.F. Denig, F.J. Rich, O, del la Beaujardiere, J.M. Ruohoniemi, A.S. Rodger, G. Crowley, B.-H. Ahn, D.S, Evans, T.J. Fuller-Rowell, E. Friis-Christiansen, M. Lockwood, H. Kroehl, C. McClennan, A, McEwin, R.J. Pellinen, R.J. Morris, G.B. Burns, V. Papitashvili, A.Zaitzev, O. Troshichev, N. Sato, P. Sutcliffe, L. Tomlinson, Ionospheric convection response to strong, slow variations in a northward intreplanetary magnetic field: A case study for January 14, 1988, J. Geophys. Res., 98, 19,273-19,292, 1993.

Knipp, D.J., A.D. Richmond, B. Emery, N.U. Crooker, O.de la Beaujardiere, D. Evans, and $\mathrm{H}$. Kroehl, Ionospheric convection response to changing IMF direction, Geophys. Res. Lett., 18, 721-724, 1991a.

Knipp, D.J. A.D. Richmond, and N.U. Crooker, Reply to the comment by Lockwood and Cowley on "Ionospheric convection response to changing IMF direction", Geophys. Res. Lett., 18, 2175-2176, 1991b.

Koskinen, H.E.J., R.E. Lopez, R.J. Pellinen, T.I. Pulkkinen, D.N. Baker, and T. Bösinger, Pseudobreakup and substorm growth phase in the ionosphere and magnetosphere, J, Geophys. Res., 98, 5801-5813, 1993.

Kozelova T., A. Melnikov, T. Kornilova, and M. Pudovkin, Aurora dynamics, high energy electron precipitation and magnetic field configuration changes at $6.6 \mathrm{R}_{\mathrm{e}}$ for various intensity substorms, Adv. Space Res., 13, (4)93-(4)97, 1993.

Kozelova, T.A., M.N. Pudovkin, T.A. Kornilova, and A.O. Mel'nikov, Peculiarities of substorms which develop in the part of the current layer close to the earth, Geomagn. \& Aeron. 31, 790-794, 1991.

Krymskiy, P.F. and V.M. Filippov, The generation of electric field near the plasmopause during magnetospheric disturbances, Geomagn. \& Aeron. 31, 441-443, 1991.

Laakso, H., A. Pedersen, J.D. Craven, and L.A. Frank, Magnetospheric electric fields and auroral oval, in "Substorms 1, Proceedings of the First International Conference on Substorms, ICS-I", ed C. Mattock, ESA-SP-335, 499-504, European Space Agency Publications, Nordvijk, The Netherlands, 1992.

Lakhina, G.S., A kinetic theory of driven reconnection in the earth's magnetotail, J. Geophys, Res., 97, 2961-2972, 1992.

Lakhina, G.S., On the ion tearing instability of forced current sheets, J. Geophys. Res., 98 , 17409-17413, 1993.

Lanzerotti, L.J., R.M. Konik, A. Wolfe, D. Venkatesan, and C.G. Maclennan, Cusp latitude magnetic impulse events 1. Occurrence statistics, J. Geophys. Res., 96, 14,009-14,022. 1991.

Le, G., C.T. Russell, and H. Kuo, Flux transfer events: spontaneous or driven? Geophys. Res. Lett, 20, 791-794, 1993.

Lee, L.C., and C.Q. Wei, Interaction of solar wind with the magnetopause-boundary layer and generation of magnetic impulse events, J. Atmos. Terr. Phys. 55, 967-978, 1993.

Lee, D-Y., and R.A. Wolf, Is the earth's magnetotail balloon unstable? J. Geophys. Res., 97, 19,251-19,257, 1992.

Lennartsson, W., A scenario for solar wind penetration of earth's magnetic tail based on ion composition data from the ISEE 1 spacecraft, J. Geophys. Res., 97, 19,221-19,238, 1992. 
Leontyev, S.V., G.V. Starkov, V.G. Vorobjev, and V.L. Zverev, Dayside aurorae and their relations to other geophysical phenomena, Planet. Space Sci., 40, 621-639, 1992.

Lester, M., O. de la Beaujardiere, J.C. Foster, M.P. Freeman, H. Lühr, J.M. Ruohoniemi, and W. Swider, The response of the large scale ionospheric convection pattern to changes in the IMF and substorms: results from the SUNDIAL 1987 campaign, Ann. Geophys. 11, 556$571,1993$.

Lewis, R.V., P.J.S. Williams, T.K. Yeoman, M. Lester, and E. Nielsen, Measurements of bursts in plasma velocity during substorm activity, Adv. Space Sci., 13, (4)139-(4)142, 1993.

Lewis, Z.V., On the apparent randomness of substorm onset, Geophys. Res. Lett., 18 , 1627-1630, 1991.

Lewis, Z.V., Convecting towards the catastrophe of substorm onset, J. Atmos. Terr. Phys., 55, 1185-1192, 1993.

Li, X., and T.W. Speiser, An estimation of the electric field in the magnetotail current sheet using the observed energetic ion bulk flow, Geophys. Res. Lett., 18, 1967-1970, 1991.

Lin, N., R.L. McPherron, M.G. Kivelsen, and R.J. Walker, Multipoint reconnection in the near-earth magnetotail: CDAW 6 observations of energetic particles and magnetic field, $J$. Geophys. Res., 96, 19,427-19,439, 1991.

Lin, Y., and L.C. Lee, Structure of the dayside reconnection layer in resistive MHD and hybrid models, I. Geophys. Res., 98, 3919-3934, 1993.

Liu, W.W., and G. Rostoker, Effects of dawn-dusk pressure asymmetry on convection in the central plasma sheet, J. Geophys. Res., 96, 11,501-11,512, 1991.

Liu, Z.X., Z.W. Zhu, F.Li., and Z.Y. Pu, Topology and signatures of a model for flux transfer events based on vortex-induced reconnection, J. Geophys. Res., 97, 19,351-19,361, 1992.

Lockwood, M., The excitation of ionospheric convection, J. Atmos. Terr. Phys., 53, 177 199, 1991a.

Lockwood, M., Flux transfer events at the dayside magnetopause: transient reconnection or magnetosheath dynamic pressure pulses?, J. Geophys. Res., 96, 5497-5509, $1991 \mathrm{~b}$.

Lockwood, M., On flow reversal boundaries and transpolar voltage in average models of high-latitude convection, Planet. Space Sci,, 39, 397-409, 1991c.

Lockwood, M., Incoherent scatter radar measurements of the cusp, in "CLUSTER dayside polar cusp", ed. C.I Barron, ESA SP-330, 57-66, European Space Agency Publications, Nordvijk, The Netherlands, 1991d.

Lockwood, M., and S.W.H. Cowley, Comment on "Ionospheric convection response to changing IMF direction" by Knipp et al., Geophys. Res. Lett., 18, 2173-2174, 1991.

Lockwood, M., and S.W. Cowley, Ionospheric convection and the substorm cycle, in "Substorms 1, Proceedings of the First International Conference on Substorms, ICS-1", ed C. Mattock, ESA-SP-335, 99-110, European Space Agency Publications, Nordvijk, The Netherlands, 1992.

Lockwood, M. and M.P. Freeman, Recent ionospheric observations relating to solar-wind-magnetosphere coupling, Phil. Trans. R. Soc., London, A., 328, 93-105, 1989.

Lockwood, M. and M.F. Smith, Low altitude signatures of the cusp and flux transfer events, Geophys. Res. Lett., 16, 879-882, 1989.

Lockwood, M., and M.F. Smith, The variation of reconnection rate at the dayside magnetopause and cusp ion precipitation, J. Geophys. Res., 97, 14,841-14,847, 1992.

Lockwood, M, and M.F. Smith, Comment on "Mapping the dayside ionosphere to the magnetosphere according to particle precipitation characteristics" by Newell and Meng, 
Geophys. Res, Lett., 20, 1739-1740, 1993.

Lockwood, M. and M.F. Smith, Low- and mid-altitude cusp particle signatures for general magnetopause reconnection rate variations: I - Theory, J. Geophys. Res., 99, 8531-8555, 1994.

Lockwood, M., and M.N. Wild, On the quasi-periodic nature of magnetopause flux transfer events, J. Geophys. Res., 98, 5935-5940, 1993.

Lockwood, M., H.C. Carlson, Jr., and P.E. Sandholt, The implication of the altitude of transient 630nm dayside auroral emissions, J. geophys. Res., 98, 15571-15587, 1993a.

Lockwood, M., S.W.H. Cowley, and M.P. Freeman, The excitation of plasma convection in the high latitude ionosphere, J. Geophys. Res., 95, 7961-7971, 1990.

Lockwood, M., S. W. H. Cowley, P. E. Sandholt, and R. P. Lepping, The ionospheric signatures of flux transfer events and solar wind dynamic pressure changes, J. Geophys. Res., 95, 17113-17135, 1990.

Lockwood, M., S.W.H. Cowley, H. Todd, D.M. Willis and C.R. Clauer, Ion flows and heating at a contracting polar cap boundary, Planet. Space Sci., 36, 1229-1253, 1988

Lockwood M., W.F. Denig, A.D. Farmer, V.N. Davda, S.W. Cowley, and H. Lühr, Ionospheric signatures of pulsed reconnection at the earth's magnetopause,

Nature, 361, 424-427, 1993 b.

Lockwood, M., A.P, van Eyken, B.J.I. Bromage, D.M. Willis, and S.W.H. Cowley, Eastward propagation of a plasma convection enhancement following a southward turning of the interplanetary magnetic field, Geophys. Res. Lett., 13, 72-75, 1986.

Lockwood, M., J. Moen, S.W.H. Cowley, A.D. Farmer, U.P. Løvhaug, H. Lühr and V.N. Davda, Variability of dayside convection and motions of the cusp/cleft aurora, Geophy. Res. Lett., 20, 1011-1014, 1993c.

Lockwood, M., P.E. Sandholt and S.W.H. Cowley, Dayside auroral activity and magnetic flux transfer from the solar wind, Geophys. Res. Lett., 16, 33-36, 1989a.

Lockwood, M., P.E. Sandholt, S.W.H. Cowley and T. Oguti, Interplanetary magnetic field control of dayside auroral activity and the transfer of momentum across the dayside magnetopause, Planet. Space Sci., 37, 1347, 1989b.

Lopez, R.E., On the location of the substorm initiation region, Adv. Space Res.,13, (4)189-(4)198, 1993.

Lopez R.E., H.E. Spence and C.-I. Meng, Substorm aurorae and their connection to the inner magnetopshere, J. Geomag. Geoelectr.,44, 1251-1260, 1992.

Lopez, R.E., H.E.J. Koskinen, T.I. Pulkkinen, T. Bosinger, R.W. McEntire, and T.A. Potemra, Simultaneous observation of the poleward expansion of substorm electrojet activity and the tailward expansion of current sheet disruption in the near-earth magnetotail, $J$. Geophys. Res., 98, 9285-9295, 1993.

Lopez, R.E., H.E. Spence, and C.-I. Meng, DMSP F7 Observations of a substorm fieldaligned current, J. Geophys. Res., 96, 19,409-19,415, 1991.

Lotko, W., B.U.O. Sonnerup and R.L. Lysak, Non-staedy boundary layer flow including ionospheric drag and parallel electric fields, J. Geophys. Res., 92, 8635-8648, 1987.

Lotko, W., and M.-M. Shen, On large-scale rotational motions and energetics of auroral shear layers, J. Geophys. Res., 96, 9549-9565, 1991.

Lu, G., P.H. Reiff, J.L. Burch, and J.D. Winningham, on the voltage-current relationship, J. Geophys. Res., 96, 3523-3532, 1991.

Lühr, H., W. Blawert, H. Todd, The ionospheric plasma flow and current patterns of travelling convection vortices: a case study, J, Atmos. Terr. Phys., 55, 1717-1727, 1993.

Lui, A.T.Y., Stability of the earth's neutral sheet, Adv. Space Res., 11, (9)161-(9)165, 
$1991 \mathrm{a}$.

Lui, A.T.Y., A synthesis of magnetospheric substorm models, J. Geophys. Res., 96, 1849 1856, $1991 \mathrm{~b}$.

Lui, A.T.Y., What determines the intensity of magnetospheric substorms?, J. Atmos. Terr. Phys., 55, 1123-1136, 1993.

Lui, A.T.Y., and D.G. Sibeck, Dayside auroral activities and their implications for impulse entry processes in the dayside magnetosphere, J. Atmos. Terr. Phys., 53, 219-229, 1991.

Lui, A.T.Y., C.-L. Chang, A. Mankofsky, H.-K. Wong, and D. Winske, A cross-field current instability for substorm expansions, J. Geophys. Res., 96, 11,389-11,401, 1991.

Lui, A.T.Y., R.E. Lopez, B.J. Anderson, K. Takahashi, L.J. Zanetti, R.W. McEntire, T.A. Potemra, D.M. Klumpar, E.M. Greene, and R. Strangeway, Current disruption in the nearearth neutral sheet region, J. Geophys. Res., 97, 1461-1480, 1992.

Lummerzheim, D,, M.H. Rees, J.D. Craven, and L.A. Frank, Ionospheric conductances derived from DE-1 auroral images, J. Atmos. Terr. Phys., 53, 281-292, 1991.

Lyons, L.R. and C.Y. Huang, Observations of plasma sheet expansion at substorm onset, $\mathrm{R}=15$ to $22 \mathrm{R}_{\mathrm{e}}$, Geophys. Res. Lett., 19, 1807-1810, 1992.

Lyons, L.R. and D.C. Pridmore-Brown, Force balance near an X line along which E.J < 0, J. Geophys. Res., 97, 2955-2960, 1992.

Lysak, R.L., and D.-H. Lee, Response of the dipole magnetosphere to pressure pulses, Geophys. Res. Lett., 19, 937-940, 1992.

Lysak, R.L., J. Grieger, and Yan Song, Fast ionospheric feedback instability and substorm onset, in "Substorms 1, Proceedings of the First International Conference on Substorms, ICS$I^{\prime \prime}$, ed C. Mattock, ESA-SP-335, 231-236, European Space Agency Publications, Nordvijk, The Netherlands, 1992.

Ma, Z.A., J.G. Hawkins, and L.C. Lee, A simulation study of impulsive penetration of solar wind irregularities into the magnetosphere at the dayside magnetopause, I. Geophys. Res., 96, 15,751-15,765, 1991.

Macek, W.M. and S.W.H. Cowley, On a steady -state plasma sheet in the distant magnetotail, Planet. Space Sci., 40, 27-32, 1992.

Maclennan, C.G., L.J. Lanzerotti, S.-I. Akasofu, A.N. Zaitzey, P.J. Wilkinson, A. Wolfe, and V. Popov, Comparison of "Electrojet" indices from the northern and southern hemispheres, J. Geophys. Res., 96, 267-274, 1991.

Makita K., C.-I. Meng, and S.-I, Akasofu, Transpolar auroras, their particle precipitation, and IMF By component, J. Geophys. Res., 96, 14,085-14,095, 1991.

Mal'kov, M.V., and V.A. Sergeev, Characteristic anomalies of the magnetospheric configuration under stable convection activity, Geomagn. and Aeron., 31, 578-580, 1991.

Marklund G., Viking investigations of auroral electrodynamical processes, J. Geophys. Res., 98, 1691-1704, 1993.

Marklund G., High-latitude convection and auroral electrodynamics, in "Substorms I, Proceedings of the First International Conference on Substorms, ICS-I", ed C. Mattock, ESASP-335, 89-98, European Space Agency Publications, Nordvijk, The Netherlands, 1992.

Marklund, G.T., and L.G. Blomberg, On the influence of localized electric fields and fieldaligned currents associated with polar arcs on the global potential distribution, J. Geophys. Res., 96, 13,977-13,983, 1991.

Marklund, G.T., L.G. Blomberg, J.S. Murphree, R.D. Elphinstone, L.J. Zanetti, R.E. Erlandson, I. Sandahl, O. de la Beaujardiere, H. Opgenoorth, and F.J. Rich, On the electrodynamical state of the auroral ionosphere during northward interplanetary magnetic 
field: a transpolar arc case study, J. Geophys. Res., 96, 9567-9578, 1991.

Maynard, N.C., T.L. Aggson, E.M. Basinska, W.J.Burke, P. Craven, W.K. Peterson, M. Sugiura, and D.R. Weimer, Magnetospheric boundary dynamics: DE1 and DE2 observations near the magnetopause and cusp, J. Geophys. Res., 96, 3505-3522, 1991.

Mavromichalaki, H., and A. Belehaki, Mechanisms and time-scales of the magnetospheric response to the interplanetary magnetic field changes during 8 May 1986 substorm, J. Atmos. Terr. Phys., 55, 1459-1467, 1993.

McDairmid, I.B., J.R. Burrows and M.D. Wilson, Magnetic field perturbations in the dayside cleft and their relationship to the IMF, J. Geophys. Res., 83, 5357, 1978.

McHenry, M. A. and C. R. Clauer, Modeled ground magnetic signatures of flux transfer events, J. Geophys. Res., 92, 11231-11240, 1987.

McPherron, R.L., and D.N. Baker, Factors influencing the intensity of magnetospheric substorms, J. Atmos. Terr. Phys., 55, 1091-1122, 1993.

McPherron, R.L., and G. Rostoker, Comment on "Prediction of geomagnetic activity" by C.K. Goertz, Lin-Hua Shan, and R.A. Smith, J. Geophys. Res., 98, 7685-7686, 1993

McPherron R.L., V. Angelopoulos, D.N. Baker, and E.W. Hones, Jnr., Is there a near-earth neutral line? Adv. Space Res., 13, (4)173-(4)186, 1993.

Mezentsez, A.V., Regions of the development of a Kelvin-Helmholtz instability and the electrical potential distribution at the magnetosphere boundary, Geomagn. \& Aeron., 31, 269$271,1991$.

Mishin V.V., Accelerated motions of the magnetopause as a trigger of the KelvinHelmholtz instability, J. Geophys. Res., 98, 21365-21372, 1993.

Mishin V.M., T.I. Saifudinova, A.D. Bazarzhapov, D.Sh. Shirapov and S.B. Linyushkin, The magnetospheric substorm scenario "with two active phases", in "Substorms I, Proceedings of the First International Conference on Substorms, ICS-1", ed C. Mattock, ESASP-335, 297-302, European Space Agency Publications, Nordvijk, The Netherlands, 1992a.

Mishin, V,, J. Woch, L. Eliasson, T. Saifudinova, A. Bazarzhapov, D. Shirapov, and S.Lunyushkin., Substorm scenario with two active phases: a study of CDAW 9C events, in "Substorms 1, Proceedings of the First International Conference on Substorms, ICS-I", ed C. Mattock, ESA-SP-335, 383-390, European Space Agency Publications, Nordvijk, The Netherlands, 1992b.

Mishin, V.M., A.D. Bazarzhapov, T.I. Saifudinova, S.B. Lunyushkin, D. Sh. Shirapov, J. Woch, L. Eliasson, H. Opgenoorth, and J.S. Murphree, Different methods to determine the polar cap area, J. Geomag. Geoelectr., 44, 1207-1214, 1992c.

Minow J.I., and R.W. Smith, Optical remote sensing of the ion convection pattern in the high-latitude ionosphere from a polar orbiting satellite, Geophys. Res. Lett., 20, 559-562, 1993.

Miura A., Kelvin-Helmholtz instability at the magnetospheric boundary: dependence on the magnetosheath sonic Mach number, J. Geophys. Res., 97, 10,655-10,675, 1992.

Moen, J., W.J. Burke and P.E. Sandholt, A rotating midday auroral event with northward IMF, J. Geophys. Res., 98, 13,731-13,740, 1993.

Moldwin, M.B., and W.J. Hughes, Plasmoids as magnetic flux ropes, J. Geophys. Res., 96, 14,051-14,064, 1991.

Moldwin, M.B., and W.J. Hughes, Multi-satellite observations of plasmoids: IMP 8 and ISEE 3, Geophys. Res. Lets., 19, 1081-1084, 1992a.

Moldwin, M.B. and W.J. Hughes, Plasmoid observations in the distant plasma sheet boundary layer, Geophys. Res. Lett., 19, 1911-1914, 1992 b. 
Moldwin, M.B., and W.J. Hughes, On the formation and evolution of plasmoids: A survey of ISEE 3 geotail data, I. Geophys. Res., 97, 19,259-19,282, 1992c.

Moldwin, M.B., and W.J. Hughes, Geomagnetic substorm association of plasmoids, $J$. Geophys, Res., 98, 81-88, 1993.

Morelli, J.P., R.J. Bunting, S.W.H. Cowley, C.J. Farrugia, M.P. Freeman, E. FriisChristensen, G.O.L. Jones, M. Lester, R.V. Lewis, H. Lühr, D. Orr, M. Pinnock, G.D. Reeves, P.J.S. Williams, and T.K.Yeoman, Plasma flow bursts in the nightside auroral zone ionosphere and their relation to geomagnetic activity, Adv. Space Res., 13, (4)135-(4)138, 1993.

Moses, J.J., G.L, Siscoe, R.A. Heelis, and J.D. Winningham, Polar cap deflation during magnetospheric substorms, J. Geophys. Res., 94, 3785-3789, 1989.

Murphree, J.S., and L.L. Cogger, Observations of substorm onset, in "Substorms I, Proceedings of the First International Conference on Substorms, ICS-1", ed C. Mattock, ESA$S P-335,207-212$, European Space Agency Publications, Nordvijk, The Netherlands, 1992.

Murphree J.S., R.D. Elphinstone, M.G. Henderson, L.L. Cogger, and D.J.Hearn, Interpretation of optical substorm onset observations, J. Atmos. Terr. Phys., 55, 1159-1170, 1993.

Nakai H., Y. Kamide, and C.T. Russell, Influences of solar wind parameters and geomagnetic activity on the tail lobe magnetic field: a statistical study, J. Geophys. Res., 96, 5511-5525, 1991.

Nakumara, R., T. Oguti., T. Yamamoto, and S. Kokubun, Equatorward and poleward expansion of the auroras during auroral substorms, J. Geophys. Res., 98, 5743-5759, 1993.

Nakamura, M., G. Paschmann, W. Baumjohann, and N. Sckopke, Ion distributions and flows in and near the plasma sheet boundary layer, J. Geophys. Res., 97, 1449-1460, 1992.

Nakumura, R., D.N. Baker, D.H. Fairfield, D.G. Mitchell, and R.L. McPherron, Plasma flows and magnetic field characteristics in the midtail region, Adv. Space Res., 13, (4)223(4) $228,1993$.

Newell, P. T. and C. I. Meng, Ion acceleration at the equatorward edge of the cusp: low altitude observations of patchy merging, Geophys. Res. Lett, I8, 1829-1832, 1991.

Newell, P.T. and C.-I. Meng, Mapping the dayside ionosphere to the magnetosphere according to particle precipitation characteristics, Geophys. Res. Lett., 19, 609-612, 1992.

Newell, P.T. W.J. Burke, E.R. Sanchez, Ching-1. Meng, M.E. Greenspan, and C.R. Clauer, The low-latitude boundary and the boundary plasma sheet at low altitude: prenoon precipitation regions and convection reversal boundaries, J. Geophys, Res., 96, 21,01321,023, 1991.

Nielsen, E., Oval intensification event observed by STARE and Viking, J. Geophys. Res., 98, 6163, 1993.

Nishida, A., Ionospheric signatures of random reconnection on the dayside magnetopause, J. Atmos. Terr. Phys., 53, 213-217, 1991.

Nishida, A., T. Mukai, H. Hayakawa, A. Matsuoka, and K. Tsuruda, Unexpected features of the ion precipitation in the so-called cleft/low-latitude boundary layer region: association with sunward convection and occurrence on open field lines, J. Geophys. Res., 98, 11,16111,176, 1993.

Ohtani S., S. Kokubun, and C.T. Russell, Radial expansion of the tail current disruption during substorms: a new approach to the substorm onset region, J. Geophys. Res., 97, 31293136, 1992a.

Ohtani S., K. Takahashi, L.J. Zanetti, T.A. Potemra, and R.W. McEntire, Initial signatures of magnetic field and energetic particle fluxes at tail reconfiguration: explosive growth phase, 
J. Geophys. Res., 97, 19,311-19,324, 1992 b.

Okada T., Hayakawa, K.Tauruda, A. Nishida, and A. Matsuoka, EXOS-D observations of the enhanced electric fields during the giant magnetic storm in March 1989, J. Geophys. Res., 98, 15417-15424, 1993.

Onsager T.G., C.A. Kletzing, J.B. Austin, and H. MacKiernan, Model of magnetosheath plasma in the magnetopshere: Cusp and mantle particles at low-altitudes, Geophys. Res. Lett., 20, 479-482, 1993a.

Onsager, T.G., M.F. Thomsen, R.C. Elphic, and J.T. Gosling, Model of electron and ion distributions in the plasma sheet boundary layer, J. Geophys. Res., 96, 20,999-21,011, 1991.

Otto, A, and U. Arendt, Numerical cimulation of flux transfer events at the magnetopause: electron dynamics, Adv. Space Res., 11, (9)129-(9)132, 1991.

Owen, C.J. and S.W.H. Cowley, Heikkila's mechanism for impulsive plasma transport through the magnetopause: A reexamination, J. Geophys. Res., 96, 5565-5574, 1991.

Owen C.J., S.W.H. Cowley, Reply, J. Geophys. Res., 97, 1641-1643, 1992.

Owen, C.J. and J.A. Slavin, Viscously driven plasma flows in the deep geomagnetic tail, Geophys. Res. Lett., 19, 1443-1446, 1992.

Owen, C.J., and J.A. Slavin, Energetic ion events associated with travelling compression regions, in "Substorms 1, Proceedings of the First International Conference on Substorms, ICS-I", ed C. Mattock, ESA-SP-335, 365-370, European Space Agency Publications, Nordvijk, The Netherlands, 1992.

Paschmann, G., W. Baumjohann, N. Sckopke, T.-D. Phan, and H. Lühr, Structures of the dayside magnetopause for low magnetic shear, J. Geophys. Res., 98, 13,409-13,422, 1993.

Paschmann, G., I. Papamastorakis, W. Baumjohann, N. Sckopke, C.W. Carlson, B.U.Ö. Sonnerup, and H, Lühr, The magnetopause for large magnetic shear: AMPTE/IRM observations, J. Geophys. Res., 91, 11099-11115, 1986.

Paschmann, G., B. Sonnerup, I. Papamastorakis, W. Baumjohann, N. Sckopke, and H. Lühr, The magnetopause and boundary layer for small magnetic shear; Convection electric fields and reconnection, Geophys. Res. Lett., 17, 1829-1832, 1990.

Pedersen, A., Substorm electric and magnetic field signatures on GEOS-1, and ISEE-1, in "Substorms 1, Proceedings of the First International Conference on Substorms, ICS -1 ", ed C. Mattock, ESA-SP-335, 237-242, European Space Agency Publications, Nordvijk, The Netherlands, 1992.

Pellinen, R., How does magnetospheric convection relate to the expansion onset of substorms?, J. Atmos Terr. Phys., 55, 1137-1150, 1993.

Phillips, J.L., S.J. Barme, R.C. Elphic, J.T. Gosling, M.F. Thomsen, and T.G. Onsager, Well-resolved observations by ISEE 2 of ion dispersion in the magnetospheric cusp, $J$. Geophys. Res., 98, 13,429-13,440, 1993.

Piel, A., V. Rhode, and H. Thiemann, Plasma drifts deduced from resonance cone asymmetries: I. Theory, Adv. Space Res., 12, (6)259-(6)262, 1992a.

Piel, A., V. Rhode, H. Thiemann, and K.I. Oyama, Plasma drifts deduced from resonance cone asymmetries: II. Evaluation of corex data, Adv. Space Res., 12, (6)263-(6)266, 1992b.

Pinnock M., A.S. Rodger, J.R. Dudeney, K.B. Baker, P.T. Newell, R.A. Greenwald, and M.E. Greenspan, Observations of an enhanced convection channel in the cusp ionosphere, $J$. Geophys. Res., 98, 3767-3776, 1993.

Pinnock M., A.S. Rodger, J.R. Dudeney, R.A. Greenwald, K.B. Baker, and I.M. Ruohoniemi, An ionospheric signature of possible enhanced magnetic field merging on the dayside magnetopause, J. Atmos. Terr. Phys., 53, 201-212, 1991. 
Pivovarov, V.G., The generation of electric fields in the tail of the magnetosphere, Geomagn. and Aeron., 31, 420-423, 1991.

Pivovarov, V.G,, Mathematical model of generation of electric fields and currents in the magnetospheric tail, Adv. Space Res., 13, (4)67-(4)70, 1993.

Potemra, T.A., R.E. Erlandson, L.J. Zanetti, R.L. Arnold, J. Woch, and E. FriisChristensen, The dynamic cusp, J. Geophys. Res., 97, 2835-2844, 1992.

Potemra, T.A., L.J. Zanetti, R. Elphinstone, J.S. Murphree, and D.M. Klumpar, The pulsating magnetosphere and flux transfer events, Geophys. Res. Lett., 19, 1615-1618, 1992.

Priest, E.R., and T.G. Forbes, Magnetic flipping; reconnection in three dimensions without null points, J. Geophys. Res., 97, 1521-1531, 1992a.

Priest, E.R., and T.G. Forbes, Does fast magnetic reconnection exist? J. Geophys. Res., 97, 16,757-16,772, $1992 b$.

Pritchett, P.L., and F.V. Coroniti, Formation and stability of the self-consistent onedimensional tail current sheet, J. Geophys. Res., 97, 16,773-16,787, 1992a.

Pritchett, P.L., and F.V. Coroniti, Interaction of reflected ions with the firehose marginally stable current sheet: Implications for plasma sheet convection, Geophys. Res. Lett., 19, 16311643, $1992 b$.

Pritchett, P.L., F.V. Coroniti, R. Pellat, and H. Karimabadi, Collisionless reconnection in two-dimensional magnetotail equilibria, Phys. Res., 96, 11,523-11,538, 1991.

Pu., Z.Y., A. Korth, and G. Kremser, Plasma and magnetic field parameters at substorm onsets derived from GEOS 2 observations, J. Geophys. Res., 97, 19,341-19,349, 1992.

Pudovkin M.I., A model of the dayside magnetosphere and breakups in the cusp region, in "CLUSTER - dayside polar cusp", ed. C.I Barron, ESA SP-330, 139-145, European Space Agency Publications, Nordvijk, The Netherlands, 1991

Pudovkin, M.I., and S.A. Zaitseva, DP-Y-field-aligned currents and intensity of the $\mathrm{B}_{\mathrm{y}}$ IMF penetrated into the magnetotail, Planet. Space Sci., 41, 405-408, 1993.

Pudovkin, M.I., and V.E. Zakharov, Numerical simulations of magnetosphere-ionosphere coupling, including kinetic effects in the plasma sheet, Planet. Space Sci., 40, 1071-1080, 1992.

Pudovkin M.I., V.S. Semenov, G.V. Starkov, and T.A. Kornilova, On separation of the potential and vortex parts of the magnetotail electric field, Planet. Space Sci., 39, 563-568, 1991.

Pudovkin, M.I., S.A. Zaitseva, P.E. Sandholt, and A. Egeland, Dynamics of aurorae in the cusp region and characteristics of magnetic reconnection at the magnetopause, Planet. Space Sci., 40, 879-887, 1992.

Pulkkinen, T.I., A study of magnetic field and current configurations in the magnetotail at the time of a substorm onset, Planet. Space Sci., 39, 833-845, 1991.

Pulkkinen T.I., D.N. Baker, D.H. Fairfield, R.J. Pellinen, J.S. Murphree, R.D. Elphinstone, R.L. McPherron, J.F. Fennell, R.E. Lopez, and T. Nagai, Modelling the growth phase of a substorm using the Tsyganenko model and multi-spacecraft observations: CDAW-9, Geophys. Res. Lett., 18, 1963-1966, 1991a.

Pulkkinen, T.I., H.E.J. Koskinen, and R.J. Pellinen, Mapping of auroral arcs during substorm growth phase, J. Geophys. Res., 96, 21,087-21,094, 1991b.

Rajaram, R., Sibeck, D.G., and R.W. McEntire, Linear theory of the Kelvin- Helmholtz instability in the low-latitude boundary layer, J. Geophys. Res., 96, 9615-9625, 1991.

Reeves, G.D., Multiple substorm injections and the new substorm paradigm: Interpretation of the CDAW-7 substorm, Adv. Space Sci., 13, (4)213-(4)216, 1993. 
Reeves, G.D., G. Kettmann, T.A. Fritz, and R.D. Belian, Further investigation of the CDAW-7 substorm using geosynchronous particle data: multiple injections and their implications, J. Geophys. Res., 97, 6417-6428, 1992.

Reiff, P. H., T. W. Hill, and J. L. Burch, Solar wind plasma injection at the dayside magnetospheric cusp, J. Geophys. Res., 82, 479-491, 1977.

Reiff, P. H., J.L. Burch and R. W. Spiro, Cusp proton signatures and the interplanetary magnetic field, J. Geophys. Res., 85, 5997, 1980.

Rezhenov, B.V., Plasma convection at high latitudes, Geomagn. and Aeron., 31, 284-286, 1991.

Richardson, I., C.J. Owen, S.W.H. Cowley, A.B. Galvin, T.R. Sanderson, M. Scholer, J.A. Slavin and R.D. Zwickl, ISEE-3 observations during the CDAW-8 intervals: case studies of the distant geomagnetic tail covering a wide range of geomagnetic activity, $J$. Geophys. Res, 94, 15189, 1989.

Richmond, A.D., Assimilative mapping of ionospheric electrodynamics, Adv. Space Res., 12, (6)59-(6)68, 1992.

Rijnbeek R. P., C. J. Farrugia, D. J. Southwood, M. W. Dunlop, W. A. C. Mier-Jedrejowicz, C. P. Chaloner, D. S. Hall, and M. F. Smith, A magnetic boundary signature within flux transfer events, Planet. Space Sci., 35, 871-878, 1987.

Rijbeek, R.P., V.S. Semenov, A.A. Shmalts, H.K. Biernat, M.F. Heyn, and B.P. Besser, B.P., Time-dependent reconnection in a current sheet with velocity shear, Planet. Space Sci.. 39, 1377-1395, 1991.

Roberts, D.A., Is there a strange attractor in the magnetosphere ?, J. Geophys. Res., 96, 16,031-16,046, 1991.

Roberts, D.A., D.N. Baker, A.J. Klimas, and L.F. Bargatze, Indications of low dimensionality in magnetospheric dynamics, Geophys. Res. Lett., 18, 151-154, 1991.

Robinson, T.R., Simulation of convection flow estimation errors in VHF bistatic auroral radar systems, Annales. Geophys., 11, 1033-1050, 1993.

Rosenberg, T.J., D.L. Detrick, D. Venkatesan, and G. van Bavel, A comparative study of imaging and broad-beam riometer measurements: The effect of spatial structure on the frequency dependence of auroral absorption, J, Geophys. Res., 96, 17,793-17,803, 1991.

Rosenberg, Z. Wang, A.S. Rodger, J.R. Dudeney, and K.B. Baker, Imaging riometer and HF radar measurements of drifting $\mathrm{F}$ region electron density structures in the polar cap, $J$. Geophys. Res., 98, 7757-7764, 1993.

Rostoker, G., Low latitude signatures of substorm activity, J. Atmos. Terr, Phys., 55, 985994, 1993.

Rostoker, G., and S. Skone, Magnetic flux mapping considerations in the auroral oval and the Earth's magnetotail, J. Geophys. Res., 98, 1377-1384, 1993.

Roth, M., On impulse penetration of solar wind plasmoids into the geomagnetic field, Planet. Space Sci., 40, 193-201, 1992.

Rothwell, P.L., M.B. Silevitch, L.P. Bolck, and C,-G. Fälthammer, Prebreakup ares: a comparison between theory and experiment, J. Geophys. Res, 96, 13,967-13,975, 1991.

Ruohoniemi, J.M., R.A. Greenwald, $\mathrm{O}$ de la Beaujardiere, M. Lester, The response of the high-latitude dayside ionosphere to an abrupt northward transition in the IMF, Ann. Geophys, 11, 544-555, 1993.

Russell, C. T., and R. C. Elphic, Initial ISEE magnetometer results: Magnetopause observations, Space Sci. Rev., 22, 681-715. 1978.

Roux, A., S. Perraut, P. Robert, A. Morane, A. Pedersen, A. Korth, G. Kremser, B. 
Aparicio, D. Rodgers, and R. Pellinen, Plasma sheet instability related to the westward traveling surge, J. Geophys. Res., 96, 17,697-17,714, 1991.

Saifudinova, T.I, A.D. Bazarzhapov, D. Sh.Shirapov, S.B. Lunyushkin, and V.M. Mishin, Substorm scenario with two active phases: a study of CDAW-9 E events, in "Substorms 1, Proceedings of the First International Conference on Substorms, ICS-1", ed C. Mattock, ESA$S P-335,391-394$, European Space Agency Publications, Nordvijk, The Netherlands, 1992.

Samokhin, M.V., Deceleration of plasma in a layer of antisolar convection due to an ionospheric conductivity different from zero, Geomagn. and Aeron., 32, 47-51, 1992.

Samson, J.C., L.R. Lyons, P.T. Newell, F. Creutzberg, and B. Xu, Proton aurora and substorm intensifications, Geophys. Res. Lett., 19, 2167-2170, 1992a.

Samson, J.C., D.D. Wallis, T.J. Hughes, F. Creutzberg, J.M. Ruohoniemi, and R.A. Greenwald, Substorm intensifications and field line resonances in the nightside magnetosphere, J. Geophys. Res., 97, 8495-8518, 1992b.

Sanchez, E.R., and G.L. Siscoe, IMP 8 magnetotail boundary crossings: a test of the MHD models for an open magnetosphere, J. Geophys. Res., 95, 20,771-20,779, 1990.

Sanchez, E.R., B.H. Mauk, and C.-I. Meng, Adiabatic vs. non-adiabatic particle distributions during convection surges, Geophys. Res. Lett., 20, 177-180, 1993a.

Sanchez, E.R., B.H. Mauk, P.T. Newell, and C.-I. Meng, Low-altitude observations of the evolution of substorm injection boundaries, J. Geophys. Res., 98, 5815-1838, 1993 b.

Sanchez, E.R., G.L, Siscoe, J.T. Gosling, E.W. Hones, Jr., and R.P. Lepping, Observations of rotational discontinuity-slow expansion fan structure of the magnetotail boundary, $J$. Geophys. Res., 95, 61-73, 1990.

Sanchez, E.R., G.L. Siscoe, and C.-I. Meng, Inductive attenuation of the transpolar voltage, Geophys. Res. Lett., 18, 1173-1176, 1991.

Sandholt, P.E., Auroral electrodynamics at the cusp/cleft poleward boundary during northward interplanetary magnetic field, Geophys. Res. Lett., 18, 805-808. 1991,

Sandholt, P.E., and P.T. Newell, Ground and satellite observations of an auroral event at the cusp/cleft equatorward boundary, J. Geophys. Res., 97, 8685-8691, 1992.

Sandholt, P.E., M. Lockwood, W.F. Denig, R.C. Elphic and S. Leontjev, Dynamical auroral structure in the vicinty of the polar cusp: multipoint observations during southward and northward IMF, Ann. Geophys., 10, 483-497, 1992a.

Sandholt, P.E., J. Moen, and D. Opsvik, Periodic auroral events at the midday polar cap boundary: implications for solar wind-magnetosphere coupling, Geophys. Res. Lett., 19, 1223-1226, 1992b.

Sandholt, P.E., J. Moen, D.Opsvik, W.F. Denig, and W.J. Burke, Auroral event sequence at the dayside polar cap boundary: signature of time-varying solar wind-magnetosphereionosphere coupling, Adv. Space Res., 13, (4)7-(4)15, 1993a.

Sandholt, P.E., J. Moen, A. Rudland, D. Opsvik, W.F. Denig, and T. Hansen, Auroral event sequences at the dayside polar cap boundary for positive and negative interplanetary magnetic field $\mathrm{B}_{\mathrm{y}}, J$. Geophys. Res., 98, 7737-7755, $1993 \mathrm{~b}$.

Saroso, S., Relationship between IMF $\mathrm{B}_{\mathrm{y}}$ and geomagnetic activity in the southern polar cap, Ann. Geophys., 11, 470-478, 1993.

Sastri, J.H., K.B. Ramesh and H.N.R, Rao, Transient composite electric field disturbances near dip equator associated with auroral substorms, Geophys. Res. Lett., 19, 1451-1454, 1992a.

Sastri, J.H., K.B. Ramesh, and D. Karunakaran, On the nature of substorm-related transient electric field disturbances in the equatorial ionosphere, Planet. Space Sci., 40, 95-103, 
1992b.

Saunders, M.A. The origin of cusp Birkeland currents, Geophys. Res. Lett., 16, 151-154, 1989.

Saunders, M.A., The morphology of dayside Birkeland currents, J. Atmos. Terr. Phys., 54, 457-461, 1992.

Saunders, M.A., M.P. Freeman, D.J. Southwood, S.W.H. Cowley, M. Lockwood, J.C. Samson, C.J. Farrugia, and T.J. Hughes, Dayside ionospheric convection changes in response to long-period interplanetary magnetic field oscillations: determination of the ionospheric phase velocity, J, Geophys. Res., 97, 19,373-19,380, 1992.

Saxton, J.M. and A.J. Smith, Electric field at $L=2.5$ during geomagnetically disturbed conditions, Planet. Space Sci., 39, 1305-1320, 1991.

Schindler, K., On the role of irregularities in plasma entry into the magnetosphere, $J$. Geophys. Res., 84, 7257, 1979.

Schindler, K., Tail dynamics, in "Substorms I, Proceedings of the First International Conference on Substorms, ICS-1", ed C. Mattock, ESA-SP-335, 219-224, European Space Agency Publications, Nordvijk, The Netherlands, 1992.

Scholer, M., Strong core magnetic fields in magnetopause flux transfer events, Geophys. Res. Lett., 15, 748-751, 1988.

Scholer, M., Asymmetric time-dependent and stationary magnetic reconnection at the dayside magnetopause, I. Geophys. Res., 94, 15099-15111, 1989.

Scholer M. and R. Hautz, On acceleration of plasmoids in magnetohydrodynamic simulations of magnetotail reconnection, J. Geophys. Res., 96, 3581-3588, 1991.

Sckopke, N., Plasma structure near the low-latitude boundary layer: a rebuttal, J. Geophys. Res., 96, 9815-9820, 1991.

Scurry L., and C.T. Russell, Proxy studies of energy transfer to the magnetopshere, $J$. Geophys. Res., 96, 9541-9548, 1991.

Semenov, V.S., and V.V. Lebedeva, A model problem of the reconnection of this magnetic force tubes in the cusp region, Geomagn. and Aeron., 31, 785-789, 1991.

Semenov, V.S., I.V. Kubyshkin, H.K. Biernat, M.F. Heyn, R.P. Rijnbeek, B.P. Besser, and C.J. Farrugia, Flux transfer events interpreted in terms of a generalized model for Petschektype reconnection, Adv. Space, Res., 11, (9)25-(9)28, 1991a.

Semenov, V.S., I.V. Kubyshkin, V.V. Lebedeva, R.P. Rijnbeek, M.F. Heyn, H.K. Biernat, and C.J. Farrugia, A comparison and review of ready-state and time-varying reconnection, Planet. Space Sci., 40, 63-87, 1992 a.

Semenov, V.S., I.V. Kubyshkin, V.V. Lebedeva, M.V. Sidneva, H.K. Biernat, M.F. Heyn, B.P. Besser, and R.P. Rijnbeek, Time-dependent localized reconnection of skewed magnetic fields, J, Geophys. Res., 97, 4251-4263, 1992b.

Semenov, V.S., N.V. Yerkayev, and M.F. Kheyn, Non-stationary Petschek reconnection. convective zone, Geomagn. and Aeron., 31, 176-180, $1991 \mathrm{~b}$.

Sergeev, V.A., Tail-aurora direct relationship,

in "Substorms 1, Proceedings of the First International Conference on Substorms, ICS-1", ed C. Mattock, ESA-SP-335, 277-290, European Space Agency Publications, Nordvijk, The Netherlands, 1992.

Sergeev, V.A., R.C. Elphic, F.S. Mozer, A. Saint-Marc and J.A. Sauvard, A two-satellite study of nightside flux transfer events in the plasma sheet, Planet. Space Sci., 11, 15511572, 1992.

Shan, L.-H., C.K. Goertz, and R.A. Smith, On the embedding-dimension analysis of AE 
and AL times series, Geophys. Res. Lett., 18, 1647-1650, 1991.

Sharber J.R., E.W. Hones Jr, R.A. Hellis, J.D. Craven, L.A. Frank, N.C. Maynard, J.A. Slavin, and J. Birn, Dynamics explorer measurements of particles, fields, and plasma drifts over a horse-collar auroral pattern, J. Geomag. Geoelectr., 44, 1225-1237, 1992.

Shi, Y., C.C. Wu, and L.K.C. Lee, Magnetic field reconnection patterns at the dayside magnetospuase: an MHD simulation study, J, Geophys. Res., 96, 17,627-17,650, 1991.

Shibuya, S., A note on A-C effects on MHD dynamo in the earth's low-latitude magnetospheric bioundary layer, J. Geomag. Geoelectr., 43, 65-70, 1991.

Shumilov, O.I., O.M. Raspopov, E.A. Kasatkina, R.D. Elphinstone, and R. Kreutsberg, The dyanmics of particle precipitation in the polar cap during an SC: examination of a specific event, Geomag. and Aeron., 31, 477-484, 1991.

Sibeck, D. G., A model for the transient magnetospheric response to sudden solar wind dynamic pressure variations, J. Geophys. Res., 95, 3755-3771, 1990.

Sibeck, D.G., Transient events in the outer magnetosphere: boundary waves or flux transfer events?, J. Geophys. Res., 97, 4009-4026, 1992.

Sibeck, D.G., Transient magnetic field signatures at high latitudes, J. Geophys. Res., 98, 243-256, 1993.

Sibeck, D.G., and D.G. Croley, Jr, Solar wind dynamic pressure variations and possible ground signatures of flux transfer events, I. Geophys. Res., 96, 1669-1683, 1991.

Sibeck D.G., and M.F. Smith, Magnetospheric plasma flows associated with boundary waves and flux transfer events, Geophys, Res. Lett., 19, 1903-1906, 1992.

Sibeck, D. G., W. Baumjohann, and R. E. Lopez, Solar wind dynamic variations and transient magnetospheric signatures, Geophys. Res. Lett., 16, 13-16, 1989.

Singer, H.J. W.J. Hughes, and R.R. Anderson, Advances in substorm physics from CRRES, Adv. Space Res., 13, (4)203-(4)212, 1993.

Siscoe G., Recent activity in substorm research, Adv. Space Res., 13, (4)165-(4)172, 1993.

Siscoe, G.L. and T.S. Huang, Polar cap inflation and deflation, I. Geophys. Res., 90, 543$548,1985$.

Siscoe, G., and N. Maynard, Distributed two-dimensional region 1 and region 2 currents: model results and data comparisons, J. Geophys. Res., 96, 21,071-21,085, 1991.

Siscoe, G.L., W, Lotko, and B.U.Ö. Sonnerup, A high-latitude, low-latitude boundary layer model of the convection current system, J. Geophys. Res., 96, 3487-3495, 1991.

Slavin, J.A., M.F. Smith, E.L. Mazur, D.N. Baker, T. Iyemori, H.J. Singer, and E.W. Greenstadt, ISEE 3 plasmoid and TCR observations during an extended interval of substorm activity, Geophys. Res. Lett., 19, 825-828, 1992.

Smith, M. F. and M. Lockwood, The pulsating cusp, Geophys. Res. Lett., 17, 1069-1072, 1990.

Smith, M.F., and C.J. Owen, Temperature anistropes in a magnetospheric FTE, Geophys. Res. Lett., 19, 1907-1910, 1992.

Smith, M.F. and D.J. Rodgers, Ion distributions at the dayside magnetopause, J. Geophys. Res., 96, 11,617-11,624, 1991.

Smith, M.F., M. Lockwood, and S.W.H. Cowley, The statistical cusp: a flux transfer event model, Planet. Space Sci., 40, 1251-1268, 1992.

Song, P., and C.T. Russell, Model of the formation of the low-latitude boundary layer for strongly northward interplanetary magnetic field, J. Geophys. Res., 97, 1411-1420, 1992.

Sonnerup, B.U.Ö., I. Papamastorakis, G. Paschmann, and H. Lühr, The magnetopause for 
large magnetic shear: analysis of convection electric fields from AMPTE/IRM, J. Geophys. Res., 95, 10,541-10,557, 1990.

Southwood, D. J., Theoretical aspects of ionosphere-magnetosphere-solar wind coupling, Adv. Space Res., 5(4), 7-14, 1985.

Southwood, D. J., The ionospheric signature of flux transfer events, J. Geophys. Res., 92, 3207-3213, 1987.

Southwood, D.J., and M.G. Kivelson, Vortex motion in the ionsphere and nonlinear transport, J. Geophys. Res., 98, 11,459-11,466, 1993a.

Southwood, D.J. and M.G. Kivelson, Aspects in common of high latitude ionospheric vortex motions, Adv. Space Res., Vol 13, (4)149-(4)157, 1993 b.

Southwood, D. J., C. J. Farrugia, and M. A. Saunders, What are flux transfer events?, Planet. Space Sci., 36, 503-508, 1988.

Stasiewicz, K., A global model of gyroviscous field line merging at the magnetopause, $J$. Geophys. Res., 96, 77-86, 1991.

Stasiewicz, K., Polar cusp topology and position as a function of interplanetary magnetic field and magnetic activity: comparison with Viking and other observations, J. Geophys. Res., 96, 15789-15800, 1991.

Sun, W., J.R. Kan, and S.-I. Akasofu, Evolution of magnetic configurations in the plasma sheet during a substorm on March 19 1978, J. Geophys. Res., 96, 15,831-15,839, 1991.

Taguchi, S., M. Sugiura, J.D. Winningham, J.A. Slavin, Characterization of the IMF B dependent field-aligned currents in the cleft region based on DE 2 observations, J. Geophys. Res., 98, 1393-1407, 1993.

Todd, H., B. J. I. Bromage, S. W. H. Cowley, M. Lockwood, A. P. van Eyken, and D. M. Willis, EISCAT observations of bursts of rapid flow in the high latitude dayside ionosphere, Geophys. Res. Lett., 13, 909- 913, 1986.

Todd, H., S.W.H. Cowley, M. Lockwood, D.M. Willis, and H, Lühr, Response time of the high-latitude dayside ionosphere to sudden changes in the north-south, component of the IMF, Planet. Space Sci., 36, 1415-1428, 1988.

Toffelleto F.R, and T.W. Hill, Mapping the solar wind electric field to the Earth's polar caps, J. Geophys. Res., 94, 329-347, 1989.

Traver, D.P. D.G. Mitchell, D.J. Williams, L.A. Frank, and C.Y. Huang, Two encounters with the flank low-latitude boundary layer: further ecidence for closed field topology and investigation of the internal structure, J. Geophys. Res., 96, 21,025-21,035, 1991.

Treumann, R.A., J. La Belle, and R. Pottelette, Plasma diffusion at the magnetopause: the case of lower hybrid drift waves, J. Geophys. Res., 96, 16,009-16,013, 1991.

Ugai M., Computer simulations of field-aligned currents generated by fast magnetic reconnection in three dimensions, J. Geophys. Res., 96, 21,173-21,181, 1991.

Ullaland, S, G. Kremser, P. Tanskanen, A. Korth, A. Roux, K. Torkar, L.P. Block, and I.B. Iversen, On the development of a magnetic substorm influenced by a storm sudden commencement: ground, balloon, and satellite observations, J. Geophys. Res., 98, 15381$15402,1993$.

Valladares, C.E., and H.C. Carlson, Jr., The electrodynamic, thermal, and energetic character of intense sun-aligned arcs in the polar cap, J. Geophys. Res., 96, 1379-1400, 1991.

Vassiliadis, D., A.S. Sharma, and K. Papadopoulos, Lyapunov exponent of magnetospheric activity from AL time series, Geophys. Res. Lett., 18, 1643-1646, 1991.

Vasyliunas, V.M., Interaction between the magnetospheric boundary layers and the 
ionosphere, in "Magnetospheric Boundary layers", ESA-SP 148, 387-394, European Space Agency Publications, Nordvijk, The Netherlands, 1979.

Vennerstrøm, E. Friis-Christensen, O.A. Troshichev and V.G. Andresen, Comparison between the polar cap index PC, and the auroral electrojet indices AE, AL, and AU, $J$. Geophys. Res., 96, 101-113, 1991.

Walker, G.O., and Y.W. Wong, Ionospheric effects observed throughout East Asia of the large magnetic storm of 13-15 March 1989, J. Atmos. Ter. Phys. 55, 995-1008, 1993.

Walker, R.J., T. Ogino, M. Ashour-Abdalla, and J. Raeder, A global magnetohydrodynamic simulation of magnetospheric dynamics when the IMF is southward: mapping to the auroral zone, in "Substorms 1, Proceedings of the First International Conference on Substorms, ICS-1", ed C. Mattock, ESA-SP-335, 571-576, European Space Agency Publications, Nordvijk, The Netherlands, 1992.

Walker, R.J,, T. Ogino, J, Raeder, and M. Ashour-Abdalla, A global magnetosynamic simulation of the magnetosphere when the interplanetary magnetic field is southward: the onset of magnetotail reconnection, J. Geophys. Res.; 98, 17235-17249, 1993.

Weber, E.J., J.F. Vickery, H. Gallagher, L. Weiss, C.J. Heinselman, R.A. Heelis and M.C. Kelley, Coordinated radar and optical measurements of stable auroral arcs at the polar cap boundary, J. Geophys. Res., 96, 17,847-17,863, 1991.

Wei, C.Q. and Lee, L.C., Ground magnetic signatures of moving elongated plasma clouds, J. Geophys. Res., 95, 2405, 1990.

Wei, C.Q., and L.C. Lee, Coupling of magnetopause-boundary layer to the polar ionosphere, J. Geophys. Res., 98, 5707-5725, 1993.

Wei, C.Q., L.C. Lee, S. Wang, and S.-I. Akasofu, Evolution of magnetic flux ropes associated with flux transfer events and interplanetary magnetic events and interplanetary clouds, J. Geophys. Res., 96, 1619-1632, 1991.

Weimer, D.R., Characteristic time scales of substorm expansion and recovery, in "Substorms I, Proceedings of the First International Conference on Substorms, ICS-1", ed C. Mattock, ESA-SP-335, 551-586, European Space Agency Publications, Nordvijk, The Netherlands, 1992.

Wiemer, D.R., Substorm time constants, J. Geophys. Res., 98, 11005, 1993.

Weimer, D.R., and D.A. Gurnett, Large-amplitude auroral electric fields measured with DE 1, J. Geophys. Res., 98, 13,557-13,564, 1993.

Weimer, D.R., J.R. Kan, and S.-I. Akasofu, Variations of the polar cap potential measured during magnetospheric substorms, J. Geophys. Res., 97, 3945-3951, 1992.

Williams, P.J.S., R.V. Lewis, T.S. Virdi, M. Lester, and E. Nielsen, Plasma flow bursts in the auroral electrojets, Ann. Geophys., 10, 835-848, 1992.

Woch, J., and R. Lundin, Temporal magnetosheath plasma injection observed with Viking: a case study, Ann. Geophys., 9, 133-142, 1991.

Woch, J., and R. Lundin, Magnetosheath plasma precipitation in the polar cusp and its control by the interplanetary magnetic field, J. Geophys. Res., 97, 1421-1430, 1992a.

Woch J., and R. Lundin, Signatures of transient boundary layer processes observed with Viking, J. Geophys. Res., 97, 1431-1447, 1992 b.

Wolf R.A., R.W. Spiro, and F.J. Rich, Extension of convection modeling into the highlatitude ionosphere: some theoretical difficulties, J. Atmos. Terr. Phys., 53, 817-829, 1991.

Yagodkina, Vorobjev, V.G., S.V. Leontjev, P.E. Sandholt, and A. Egeland, Bursts of geomagnetic pulsations and their relationships with dayside auroral forms, Planet. Space Sci., 40, 1303-1309, 1992 , 
Yamauchi M., R. Lundin, and J. Woch, The IMF by effects on large-scale field-aligned currents near local noon: contributions from cusp part and non-cusp part, J. Geophys. Res., in press, 1993.

Yan, M., L.C. Lee, and E.R. Priest, Fast magnetic reconnection with small shock angles, J. Geophys. Res., 97, 8277-8293, 1992.

Yeh, H.-C., J.C. Foster, F.J. Rich, and W. Swider, Storm time electric field penetration observed at mid-latitude, J. Geophys. Res., 96, 5707-5721, 1991.

Yeoman, T.K., N. Mattin, J.M. Ruohoniemi, M. Lester, and M. Pinnock, An assessment of the $L$ shell fitting beam-swinging technique for measuring ionospheric $E$ region irregularity drift patterns, J. Geophys. Res., 97, 14,885-14,896, 1992.

Yerkayev N.V., Mechanisms of the generation of the electric field at the boundary of the earth's magnetosphere, Geomagn. \& Aeron., 31, 416-419, 1991.

Yerkayev, N.F., S. Semenov, and M.F. Kheyn, Nonstationary Petschek recombination. Diffusion region, Geomagn. \& Aeron., 31, 181-185, 1991.

Zhu, L., and R.W. Schunk, and J.J, Sojka, Field-aligned current associated with distorted two-cell convection pattern during northward interplanetary magnetic field, J. Geophys. Res., 96, 19,397-19,408, 1991.

Zhu, L., J.J. Sojka, R.W. Schunk, and D.J. Crain, A time-dependent model of polar cap arcs, J. Geophys. Res., 98, 1639-6150, 1993

Zwolakowska, D., and B. Popielawska, Tail plasma domains and the auroral oval- results of mapping based on the Tsyganenko 1989 magnetosphere model, J. Geomag. Geoelectr., 44, 1145-1158, 1992.

Zverev, V.L., and G.V. Strakov, Relation between the position of the polar boundary of the auroral oval and the substorm energy regime, Geomagn. and Aeron., 31, 280-281, 1991. 


